\title{
OPEN Optimal pulse length of insonification for Piezo1 activation and intracellular calcium response
}

\author{
Defei Liao ${ }^{1}$, Ming-Yen Hsiao ${ }^{2,3}$, Gaoming Xiang ${ }^{1}$ \& Pei Zhong ${ }^{1 凶}$
}

Ultrasound (US) neuromodulation, especially sonogenetics, has been demonstrated with potential applications in noninvasive and targeted treatment of various neurological disorders. Despite the growing interest, the mechanism for US neuromodulation remains elusive, and the optimal condition for eliciting a neural response with minimal adverse effect has not been identified. Here, we investigate the Piezo1 activation and intracellular calcium response elicited by acoustical streaming induced shear stress under various US exposure conditions. We find that Piezol activation and resultant intracellular calcium response depend critically on shear stress amplitude and pulse length of the stimulation. Under the same insonification acoustic energy, we further identify an optical pulse length that leads to maximum cell deformation, Piezo1 activation, and calcium response with minimal injury, confirmed by numerical modeling of Piezol channel gating dynamics. Our results provide insight into the mechanism of ultrasonic activation of Piezo1 and highlight the importance of optimizing US exposure conditions in sonogenetics applications.

Ultrasound (US) has recently attracted significant attention as a non-invasive modality for neuromodulation, such as in the brain and heart. US has been demonstrated to modulate excitable cells in the central ${ }^{1-6}$ and peripheral ${ }^{7-9}$ nervous systems. The unique combination of deep tissue penetration and spatial focusing capability of US has spurred increasing research activities with the hope for potential clinical treatment of Parkinson's disease, epilepsy and depression ${ }^{10}$. Despite the growing interest, the specific mechanism responsible for US neuromodulation is largely unknown, and the optimal US exposure conditions for eliciting neural response with minimal adverse effects have yet been clearly identified ${ }^{11,12}$.

Previous studies have examined the effects of pulsed ultrasound on neural activity using a wide range of insonification schemes $3,4,13,14$. Various combinations of fundamental frequency $\left(\mathrm{f}_{0}\right)$, pressure amplitude (PA), duty cycle (DC), pulse length (PL), pulse-repetition frequency (PRF), and treatment time (TT) have been evaluated. For example, Kim et al. found that 1 to $5 \mathrm{~ms}$ PL produces the strongest motor response in rats, and further speculated that increasing PL might recruit inhibitory neural circuits and thus raising the stimulation threshold ${ }^{15}$. Jan and colleagues reported that pulsed ultrasound at $300-1000 \mathrm{~Hz}$ PRF, $50 \%$ DC (corresponding to PL $=0.5$ to $1.7 \mathrm{~ms}$ ) and $200 \mathrm{~ms}$ TT produces the highest behavior response ratio in C. elegans, possibly due to the mechanical filtering effect associated with the viscoelastic properties of soft tissues ${ }^{16}$. Whilst the previous studies have attempted to determine the optimal US parameters for eliciting a specific neuroactivity, significant challenge exists in elucidating the underlying mechanism of action because of the complex biological systems involved in animal models.

To address this fundamental challenge, we investigate the effects of ultrasound on individual cells in culture, which allows us to correlate exclusively the mechanical with biological response of the cell under a broad range of insonification conditions. Specifically, we focus on Piezo $1^{17}$, one of the few eukaryotic mechanosensitive (MS) ion channels that respond distinctly to US-induced mechanical stimulations ${ }^{18-20}$. Compared with other mechanosensitive ion channels that can be activated by ultrasound, such as two pore domain $\mathrm{K}^{+} \mathrm{channels}^{21}$, voltage-gated $\mathrm{Na}^{+}$and $\mathrm{Ca}^{2+}$ channels ${ }^{22}$, and transient receptor potential (TRP) channels ${ }^{23,24}$, Piezo1 has diverse expression pattern in mammalian cells ${ }^{25}$, high specificity and sensitivity to mechanical force ${ }^{19,26}$, and more

${ }^{1}$ Department of Mechanical Engineering and Materials Science, Duke University, Durham, NC 27708, USA. ${ }^{2}$ Department of Physical Medicine \& Rehabilitation, National Taiwan University College of Medicine, Taipei, Taiwan. ${ }^{3}$ Department of Physical Medicine \& Rehabilitation, National Taiwan University Hospital, Taipei, Taiwan. ${ }^{\square}$ email: pzhong@duke.edu 
(a)

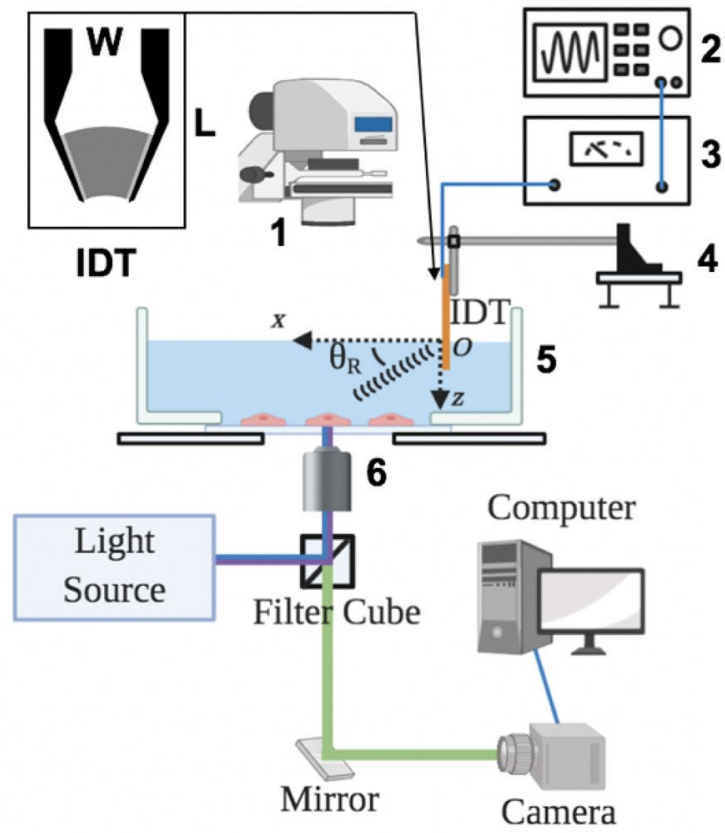

(b)

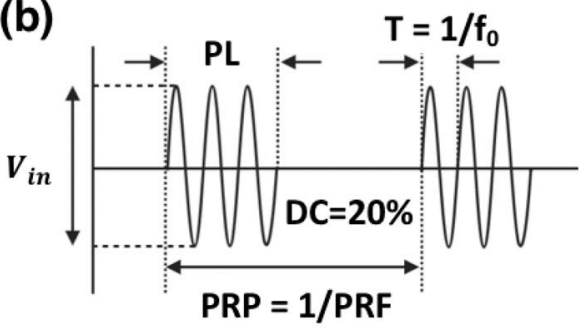

(c)

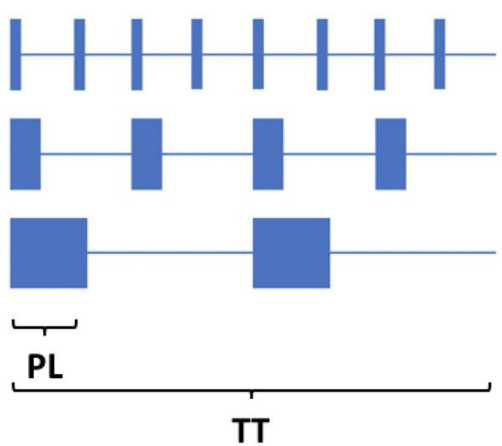

Figure 1. Piezo1 channel is activated by ultrasound with various insonification parameters, using our VD-SAW platform. (a) A schematic illustration of the combined VD-SAW transducer and fluorescent imaging system: 1: condenser, 2: function generator, 3: power amplifier, 4: three-axis micro-manipulator, 5: glass-bottom Petri dish, 6: $20 \times$ objective lens. (b) An illustration of various parameters of the ultrasound pulses: PL: pulse length, $\mathrm{T}$ : period, $\mathrm{f}_{0}$ : fundamental frequency, $\mathrm{V}_{\text {in }}$ : input voltage, $\mathrm{DC}$ : duty cycle, PRP: pulse repetition period, PRF: pulse repetition frequency. (c) Diagrams depicting different insonification protocols with varying PL while maintaining a constant total ultrasound exposure energy. TT: treatment time.

intriguingly, exhibits frequency dependent-filtering effect in response to repetitive forces ${ }^{27}$. These unique features make Piezol a strong candidate for the ideal molecular target of US neuromodulation. Recently, we have developed a novel vertically deployed surface acoustic wave (VD-SAW) platform to deliver high frequency US stimulation and acoustic streaming induced shear stresses to single HEK293T cells transfected with Piezo1 while monitoring concomitantly the cell displacement, membrane poration, and $\mathrm{Ca}^{2+}$ signaling ${ }^{28}$. We found that under the same 20\% DC and $60 \mathrm{~s}$ TT, US treatment at $100 \mathrm{~ms}$ PL (or $2 \mathrm{~Hz}$ PRF) produces much higher Piezol activation probability and intracellular calcium $\left(\left[\mathrm{Ca}^{2+}\right]_{i}\right.$ ) response than its counterpart at $1 \mathrm{~ms}$ PL (or $200 \mathrm{~Hz}$ PRF). This preliminary observation suggests that an optimal US condition may exist, leading to the highest Piezol activation probability and $\left[\mathrm{Ca}^{2+}\right]_{i}$ response.

In this study, we employ the VD-SAW platform and further broaden the parameter space to determine the safe and effective range of US exposures for Piezol activation and $\left[\mathrm{Ca}^{2+}\right]_{i}$ response in the HEK293T cells. In particular, we examined cell displacement, calcium response characteristics, membrane poration and cell detachment under shear stress produced by the VD-SAW transducer in the range of 18 to $74 \mathrm{dyne} / \mathrm{cm}^{2}$. Under the 50 dyne $/ \mathrm{cm}^{2}$ shear stress level, we further adjusted the PL over a broad range from $0.01 \mathrm{~ms}$ to $1.0 \mathrm{~s}$ to identify the optimal insonification condition for safe and effective activation of Piezo1. Moreover, we utilized a four-state model of channel gating for Piezo $1{ }^{17,27}$ with modifications to facilitate the interpretation of the PL-dependency in $\left[\mathrm{Ca}^{2+}\right]_{i}$ response observed experimentally. Altogether, our results highlight the importance of optimizing US pulsating strategy for eliciting a safe and effective calcium response in cells with mechanosensitive ion channels.

\section{Results}

Application of shear stress to single cells by VD-SAW. We utilized a 33-MHz VD-SAW transducer to produce leaky pressure waves and apply acoustic streaming-induced shear stresses to individual HEK293T adherent cells grown on the glass-bottom of a Petri dish (Fig. 1a, see also ${ }^{28}$ ). Figure $1 \mathrm{~b}$ illustrates the modulated electrical signals supplied to the VD-SAW transducer and associated parameters (input voltage $\left(\mathrm{V}_{\text {in }}\right)$, period $(\mathrm{T})$, $\mathrm{TT}, \mathrm{f}_{0}$, pulse repetition period (PRP), PL and PRF). Figure $1 \mathrm{c}$ depicts our experimental protocol for varying PL while delivering a constant total insonification acoustic energy to the target cells under the same DC (20\%) and TT $(60 \mathrm{~s})$.

We performed numerical simulations by COMSOL to calculate the pressure amplitude $\left(\left|p_{1}\right|\right)$ and streaming velocity amplitude $\left(\left|v_{2}\right|\right)$ produced by the VD-SAW transducer under continuous wave (CW) mode (Fig. 2a). The vibration amplitude of the harmonic SAW measured by a custom-built optical interferometer was input as the boundary condition in the simulation (see Supplementary Fig. S1). The pressure waveforms generated by the VD$\mathrm{SAW}$ in a water tank were also measured by a fiber optic probe hydrophone at $\mathrm{z}=3 \mathrm{~mm}$ plane. The peak pressure amplitude (1.44 MPa) and distribution along the $\mathrm{x}$-axis were found to match well with the COMSOL simulation 
(a)

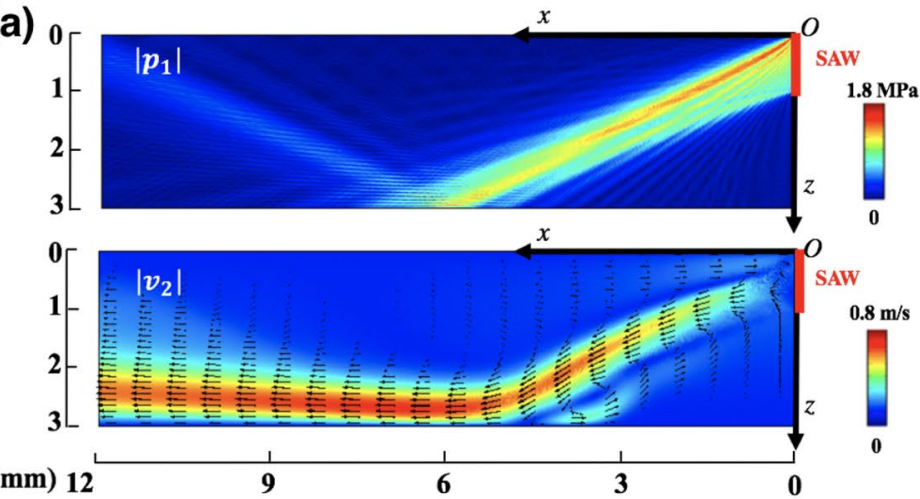

(b)

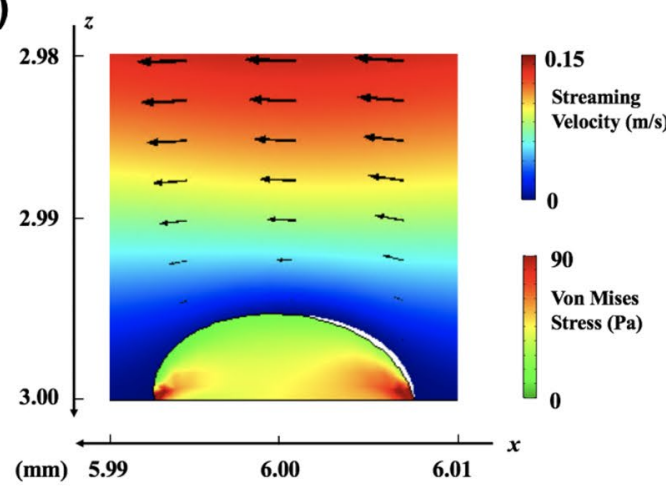

Figure 2. Numerical modeling reveals that the shear stress induced by acoustic streaming is the dominant mechanism for Piezol activation observed in the experiment. $V_{\text {in }}=80 \mathrm{mV}$ (or $\tau=50 \mathrm{dyne} / \mathrm{cm}^{2}$ ) was used as an example. (a) Finite element simulation of the acoustic field produced by VD-SAW operated under CW mode. Top: the amplitude of the first-order pressure amplitude $\left(\left|p_{1}\right|\right)$ associated with acoustic radiation force. Bottom: the amplitude of the second-order velocity $\left(\left|v_{2}\right|\right)$ associated with acoustic streaming. (b) Finite element simulation shows the distribution of von Mises stress inside an adherent cell model with its center located at $(\mathrm{x}, \mathrm{z})=(6 \mathrm{~mm}, 3 \mathrm{~mm})$ in response to streaming flow-induced shear. Black-arrow vectors indicate the direction and amplitude of the streaming velocity. White gap between the deformed cell and flow field represents the displacement of the original cell.

results in a free-field (see Supplementary Fig. S2). The shear stress $(\tau)$ at the bottom of the Petri dish near the cell surface was calculated by $\tau=\mu \frac{d v_{2}}{d z}\left(\mu\right.$ is the dynamic viscosity of water. At $20^{\circ} \mathrm{C}, \mu=1 \times 10^{-3} \mathrm{~N} \cdot \mathrm{s} \cdot \mathrm{m}^{-2}$ ). The range of shear stress produced in the target area varies from 18 to 74 dyne $/ \mathrm{cm}^{2}$ (Supplementary Fig. S3), encompassing the previously reported values for shear-induced activation of Piezol in various types of cells ${ }^{29-32}$. In contrast, the acoustic radiation force (per unit volume) produced by the VD-SAW near the cell surface was estimated to be about $2.0 \times 10^{4} \mathrm{~N} / \mathrm{m}^{328}$, which is an order of magnitude less than the threshold value $\left(1.5 \times 10^{5} \mathrm{~N} /\right.$ $\mathrm{m}^{3}$ ) reported to activate Piezol by US ${ }^{19}$. Therefore, we hypothesize that acoustic streaming-induced shear stress is the dominant factor for eliciting the calcium response in this study.

Using a $2 \mathrm{D}$ viscoelastic model of a semi-elliptical shape with semi-major axis $\mathrm{a}=7.5 \mu \mathrm{m}$ and semi-minor axis $b=5 \mu \mathrm{m}$ and associated mechanical properties relevant to HEK293T cell ${ }^{33}$, we simulated the response of an adherent cell to a constant shear flow to illustrate the salient features of their interaction (Fig. 2b). In particular, we observed inhomogeneous distribution of the von Mises stress inside the cell, with a high stress concentration built up at the leading edge, accompanied by a relatively small area of stress concentration produced at the trailing edge of the cell along the shear flow direction.

Effects of shear stress on Piezol activation and $\left[\mathrm{Ca}^{2+}\right]_{i}$. To determine the effective and safe parameter range of VD-SAW to activate Piezo1, we simultaneously treated co-cultured P1KO (piezo1 knock-out) and P1TF (piezo1 transfected) cells within the same Petri dish by various insonification protocols. We examined the effects of shear stress on Piezol activation, $\left[\mathrm{Ca}^{2+}\right]_{i}$ response, membrane poration and cell detachment. All of the cells having a normalized fluorescence $(\mathrm{F})$ ratio $\left(\left(\mathrm{F}-\mathrm{F}_{0}\right) / \mathrm{F}_{0}\right)$ above $10 \%$ of the background fluorescence $\left(\mathrm{F}_{0}\right)$ were considered as "responsive"; other cells that fell below this threshold were defined as "non-responsive".

Figure 3 shows the typical $\left[\mathrm{Ca}^{2+}\right]_{i}$ response elicited in individual P1TF cells without significant morphological change, detachment or PI uptake under four different levels of $\tau=18,28,50$, and $74 \mathrm{dyne} / \mathrm{cm}^{2}$, respectively. US pulses were applied with $100 \mathrm{~ms}$ PL, 20\% DC and $60 \mathrm{~s} \mathrm{TT}$, a protocol previously demonstrated to elicit a robust $\left[\mathrm{Ca}^{2+}\right]_{i}$ response with about $70 \%$ ratio change ${ }^{28}$. In general, despite the random variations in the shape and orientation of the cells in the target area, the $\mathrm{Ca}^{2+}$ response was mostly initiated at the leading edge of the cell (indicated by the white arrow) facing the acoustic streaming-induced shear stress (red arrow) and propagated toward the center (Supplementary Fig. S4). Quantitatively, stronger $C a^{2+}$ response was elicited by higher shear stress (Fig. 4a), reaching a plateau after $50 \mathrm{dyne} / \mathrm{cm}^{2}$. This result is presumably correlated with the large deformation of the cell membrane and resultant opening of Piezol and other mechanosensitive (MS) ion channels in the highly stressed regions $s^{24,28}$. Moreover, we calculated the intracellular $\mathrm{Ca}^{2+}$ wave speed $\left(\mathrm{C}_{I C W}\right)$ propagating from the initiation site (region (1)) to the center of the cell (region (2)) using small-region analysis ${ }^{24}$. The $C_{I C W}$ initially increased with $\tau$ before flattening out at $\sim 3 \mu \mathrm{m} / \mathrm{s}$ beyond $50 \mathrm{dyne} / \mathrm{cm}^{2}$ (Fig. $4 \mathrm{~b}$ ). Also, the $\left[\mathrm{Ca}^{2+}\right]_{i}$ response duration, measured by the full-width at half maximum (FWHM), initially increased with $\tau$ and then plateaued at $\sim 95 \mathrm{~s}$ beyond 50 dyne $/ \mathrm{cm}^{2}$ (Fig. $4 \mathrm{c}$ ). These results suggest that $\mathrm{Ca}^{2+}$ influx through Piezol ion channels might reach saturation with increased membrane tension ${ }^{27,34,35}$.

Comparing between the P1TF and P1KO groups, no substantially detectable $\mathrm{Ca}^{2+}$ response (with $\left[\mathrm{Ca}^{2+}\right]_{i}$ change exceeding $10 \%$ of the baseline value was elicited at $\tau=18 \mathrm{dyne} / \mathrm{cm}^{2}$ in either cell type (Fig. $4 \mathrm{~d}$ ). At $\geq \tau 28$ dyne $/ \mathrm{cm}^{2}$, the P1TF cells were found to have a $\mathrm{Ca}^{2+}$ response rate at least threefold higher (Fig. $4 \mathrm{~d}$ ) and a peak $\left[\mathrm{Ca}^{2+}\right]_{i}$ twofold greater than the P1KO cells (Fig. 4e), indicating that Piezol is primarily responsible for transducing the shear stress. At even higher $\tau$ from 50 to 74 dyne $/ \mathrm{cm}^{2}$, only the P1KO cells showed further increase in the $\mathrm{Ca}^{2+}$ response rate and peak $\left[\mathrm{Ca}^{2+}\right]_{i}$ value, while the response in the P1TF cells saturated. However, under such 


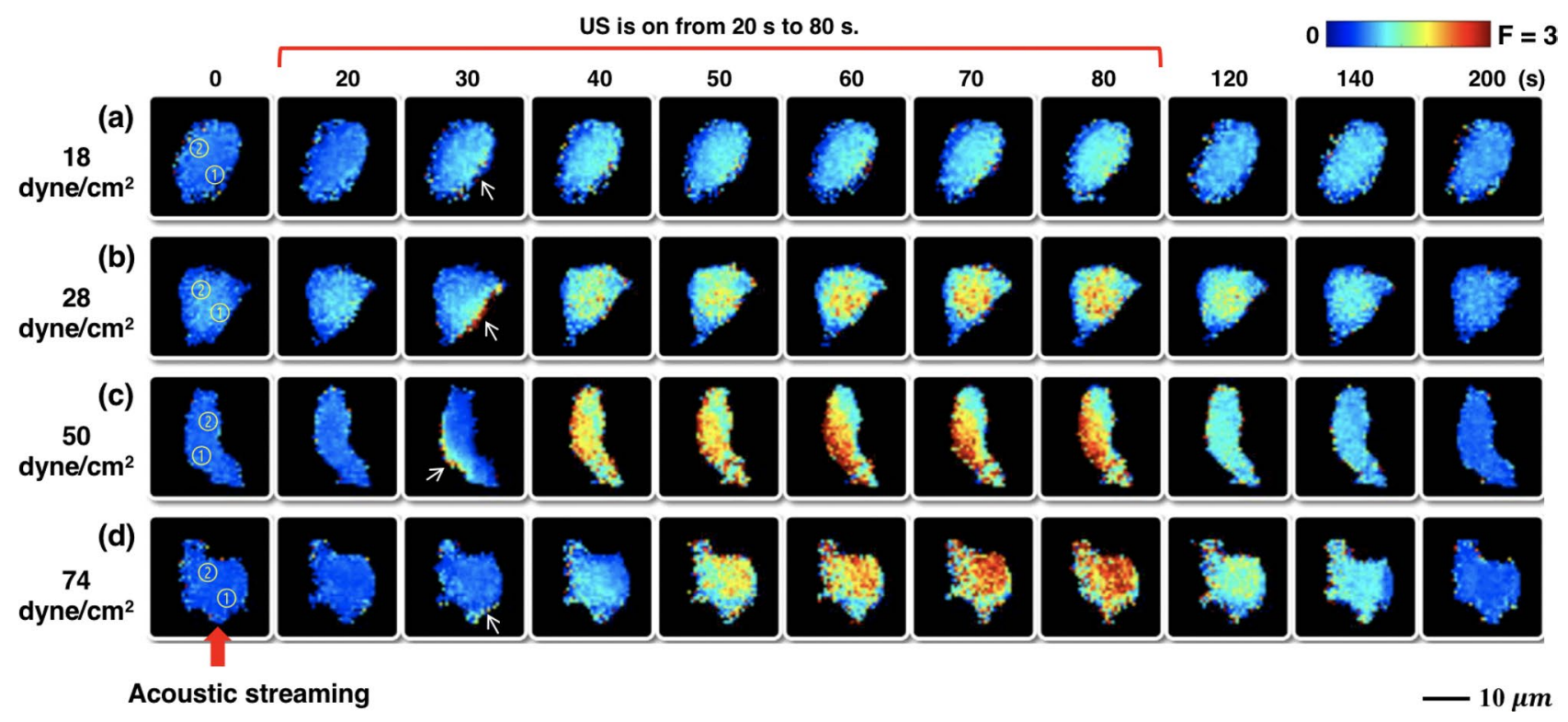

Figure 3. Sequential images show the temporal $\left[\mathrm{Ca}^{2+}\right]_{i}$ ratio change in individual P1TF cells in response to four different levels of shear stress induced by acoustic streaming under $100 \mathrm{~ms}$ PL and 20\% DC. (a) $\tau=18$ dyne $/ \mathrm{cm}^{2}$. (b) $\tau=28$ dyne $/ \mathrm{cm}^{2}$. (c) $\tau=50 \mathrm{dyne} / \mathrm{cm}^{2}$. (d) $\tau=74 \mathrm{dyne} / \mathrm{cm}^{2}$. US was on from 20 to $80 \mathrm{~s}$. Circles with numbers represents the regions used for calculating $C_{I C W}$. White arrows indicate the $\left[\mathrm{Ca}^{2+}\right]_{i}$ response initiation site. Red arrow at the bottom indicades the direction of acoustic streaming.

(a)

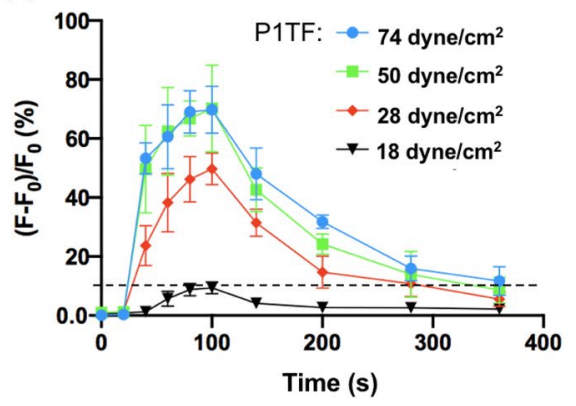

(d)

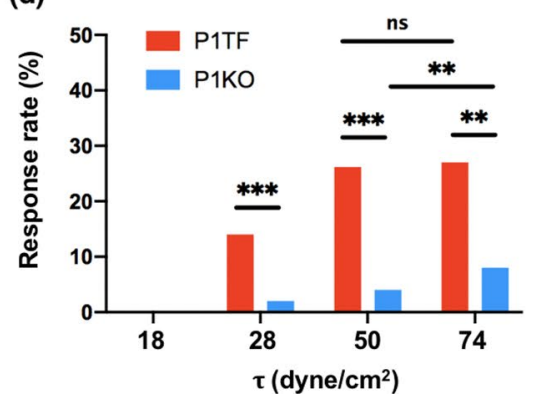

(b)

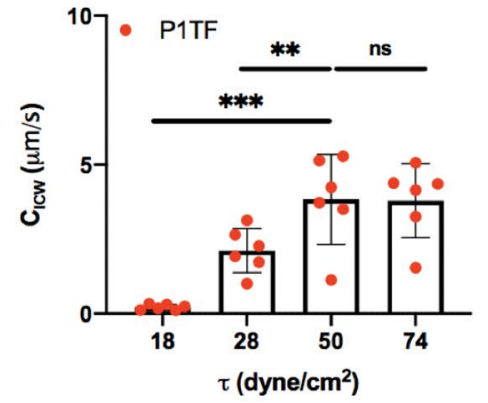

(e)

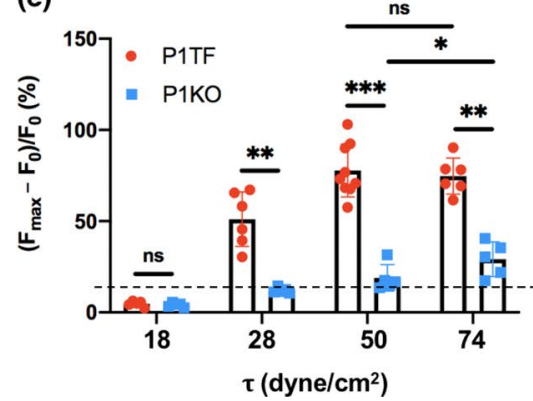

(c)

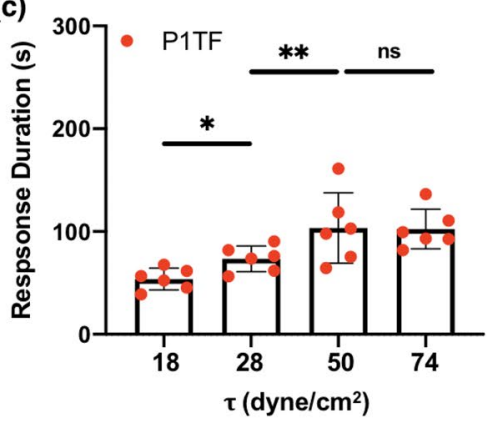

(f)

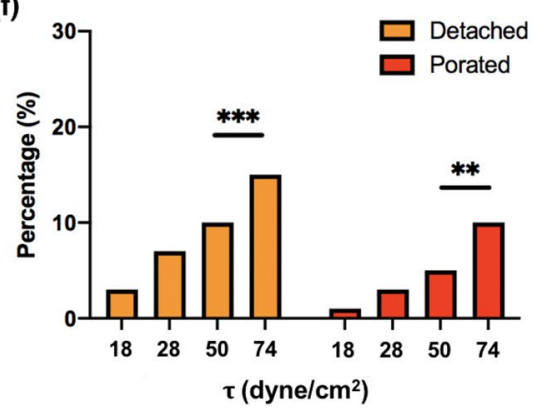

Figure 4. Piezol activation probability, $\left[\mathrm{Ca}^{2+}\right]_{i}$ characteristics, and the percentages of cell detached and membrane porated show a shear stress-dependency under $\mathrm{PL}=100 \mathrm{~ms}$. (a) The average temporal intracellular calcium ratio profile of P1TF cells in response to insonification at $100 \mathrm{~ms}$ PL, 20\% DC, $60 \mathrm{~s}$ TT but different shear stress levels. $\mathrm{n}=6$ for each data point, error bars represent \pm std. (b) Intracellular calcium wave speed $\left(C_{I C W}\right)$ in P1TF cells at different shear stress levels. $\mathrm{n}=6,{ }^{*} \mathrm{p}<0.05,{ }^{\star *} \mathrm{p}<0.01,{ }^{* *} \mathrm{p}<0.001$, and ' $\mathrm{ns}$ ' denotes not significant. Two-tailed t test. (c) Response duration in P1TF cells at different shear stress levels $(\mathrm{n}=6)$. $(\mathbf{d})$ Responsive rate of P1TF and P1KO cells at various shear stress levels ( $\mathrm{n} \sim 20$ for each bar). (e) Peak normalized intracellular calcium ratio change in P1TF and P1KO cells at various shear stress levels ( $\mathrm{n} \sim 6$ for each case). Note: the data presented in (a) to (e) were based on cells that were neither detached nor porated following insonification. (f) Percentage of detached and porated cells over all the cells in the insonified region during the experiment at different shear stress levels (total number of cells analyzed at each shear stress level in the experiment: $\mathrm{N} \sim 80)$. Two-tailed t test in $(\mathbf{b}),(\mathbf{c})$ and $(\mathbf{e})$, Fisher's exact test in $(\mathbf{d})$ and $(\mathbf{f}) .{ }^{*} \mathrm{p}<0.05,{ }^{* *} \mathrm{p}<0.01$, ${ }^{* * *} \mathrm{p}<0.001$, and ' $\mathrm{ns}$ ' denotes not significant. 


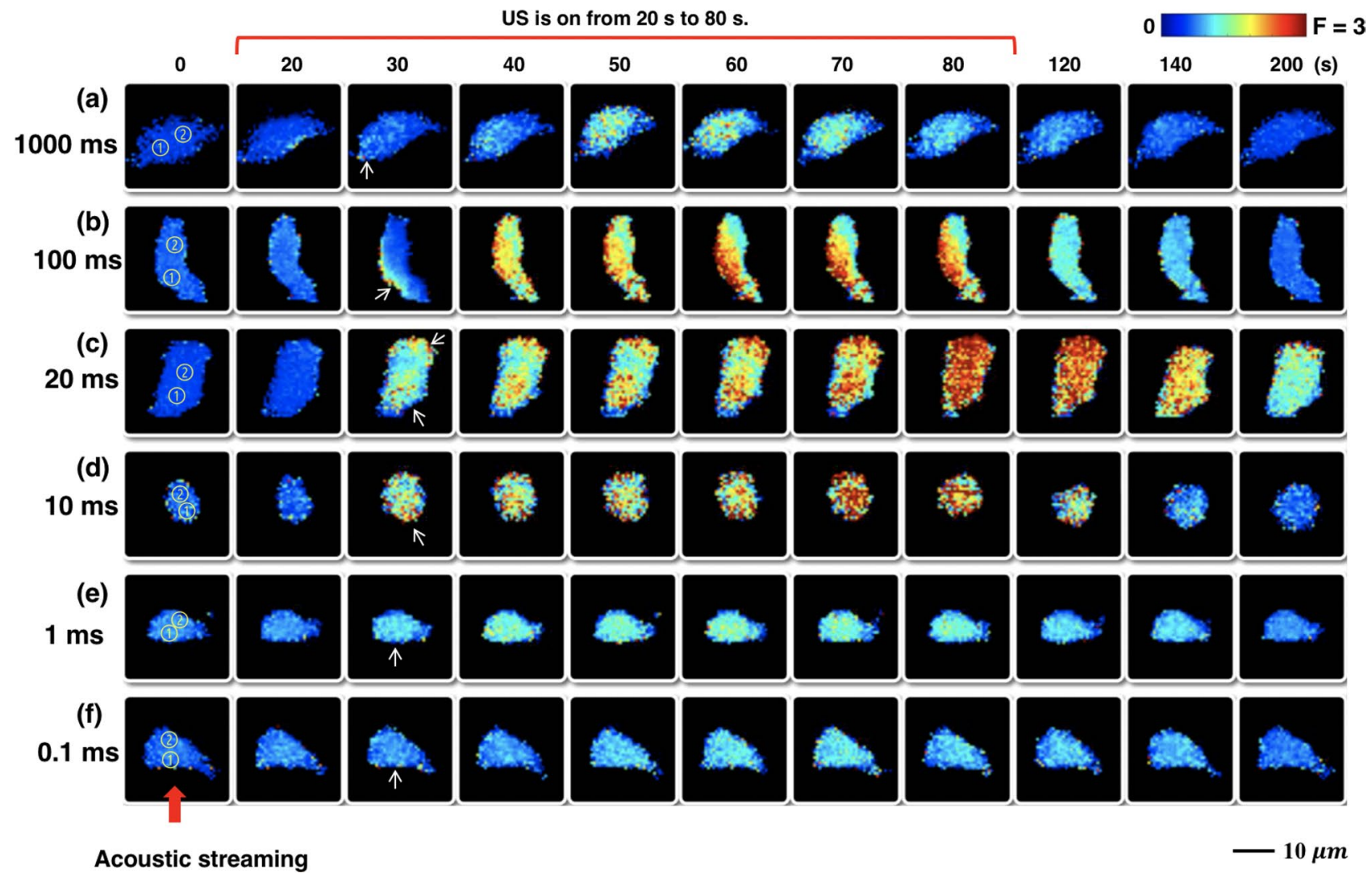

Figure 5. Sequential images show the temporal $\left[\mathrm{Ca}^{2+}\right]_{i}$ ratio change in individual P1TF cells in response to various PL. (a) $\mathrm{PL}=1000 \mathrm{~ms}$. (b) $\mathrm{PL}=100 \mathrm{~ms}$. (c) $\mathrm{PL}=20 \mathrm{~ms}$. (d) $\mathrm{PL}=10 \mathrm{~ms}$. (e) $\mathrm{PL}=1 \mathrm{~ms}$. (f) $\mathrm{PL}=0.1 \mathrm{~ms}$. Circles with numbers represents the regions used for calculating $C_{I C W}$. US was on from 20 to 80 s. White arrows indicate the $\left[\mathrm{Ca}^{2+}\right]_{i}$ response initiation sites. Red arrow at the bottom indicades the direction of VD-SAW transducer generated acoustic streaming.

high $\tau$, both the rate of cell detachment and membrane poration in the non-detached cells increased significantly (Fig. 4f), leading to a higher risk of cell injury ${ }^{36}$. For example, as $\tau$ increased from 50 to $74 \mathrm{dyne} / \mathrm{cm}^{2}$, the rate of cell detachment and membrane poration was elevated by $54 \%$ and $96 \%$, respectively.

Effects of PL on Piezo1 activation and $\left[\mathrm{Ca}^{2+}\right]_{i}$. Next, we assessed the effects of PL on Piezol activation and $\left[\mathrm{Ca}^{2+}\right]_{i}$ response at $\tau=50$ dyne $/ \mathrm{cm}^{2}$ by varying PRF in the range of $0.2 \mathrm{~Hz}$ to $20 \mathrm{kHz}$ while keeping the other US exposure parameters constant (i.e., 20\% DC and $60 \mathrm{~s}$ TT). This strategy allowed us to adjust PL in a broad range from 0.01 to $1000 \mathrm{~ms}$, which covers the full spectrum of the PL used in US neuromodulation applications ${ }^{12}$. Under such insonification conditions, negligible temperature rise $\left(<1{ }^{\circ} \mathrm{C}\right.$, see Supplementary Fig. S5), cell detachment and membrane poration $(<10 \%)$ were produced (Fig. $4 \mathrm{f})$ while effective Piezol activation could be elicited.

In general, the shear stress-elicited $\mathrm{Ca}^{2+}$ response in the P1TF cells was found to be highly sensitive to PL with the strongest $\left[\mathrm{Ca}^{2+}\right]_{i}$ change observed between 10 and $100 \mathrm{~ms}$ (Fig. 5). Outside this range at either shorter or longer PL, the elicited $\left[\mathrm{Ca}^{2+}\right]_{i}$ response became much weaker despite that the same total acoustic energy was delivered to the cells. Similar to the observations at different $\tau$ levels (Fig. 3), the initiation of $\left[\mathrm{Ca}^{2+}\right]_{i}$ elevation started at the leading edge (Fig. 5a,b,d-f) or from both the leading and trailing edges of the cell (Fig. $5 \mathrm{c}$ ) along the flow direction, and propagated toward the center. Additional experiments using the P1TF cells treated by either Thapsigargin or in calcium-free medium (Supplementary Fig. S6) indicated that this process is likely facilitated by a calcium-induced calcium release (CICR) mechanism whereby sufficient $\mathrm{Ca}^{2+}$ influx from the highly stretched plasma membrane region triggers the $\mathrm{Ca}^{2+}$ release from neighboring endoplasmic reticulums (ERs) in the cytosol, and such a diffusion-reaction process is repeated during insonification to propagate the intracellular calcium signaling 24,37 .

Quantitatively, Fig. 6a shows the average temporal profiles of $\left[\mathrm{Ca}^{2+}\right]_{i}$ change in the PITF cells elicited at different PLs. The strongest $\left[\mathrm{Ca}^{2+}\right]_{i}$ ratio change, up to nearly $90 \%$ above the baseline value, was produced by $\mathrm{PL}=20 \mathrm{~ms}$. Interestingly, the $\mathrm{C}_{\mathrm{ICW}}$ and $\left[\mathrm{Ca}^{2+}\right]_{i}$ response duration were also peaked at $\mathrm{PL}=20 \mathrm{~ms}(\mathrm{Fig} .6 \mathrm{~b}, \mathrm{c})$, and so were the response percentage and peak normalized ratio change in $\left[\mathrm{Ca}^{2+}\right]_{i}(\mathrm{Fig}$. $6 \mathrm{~d}, \mathrm{e})$. Altogether, these findings suggest that a unified mechanism may exist underlying this optimal insonification condition to produce the strongest $\left[\mathrm{Ca}^{2+}\right]$ response. It is also worth noting that at $\mathrm{PL}=20 \mathrm{~ms}$, the response percentage $(\sim 30 \%)$ of the P1TF cells is sixfold of the value $(\sim 5 \%)$ in the P1KO cells (Fig. $6 \mathrm{~d})$. Similarly, the normalized ratio change of 
(a)

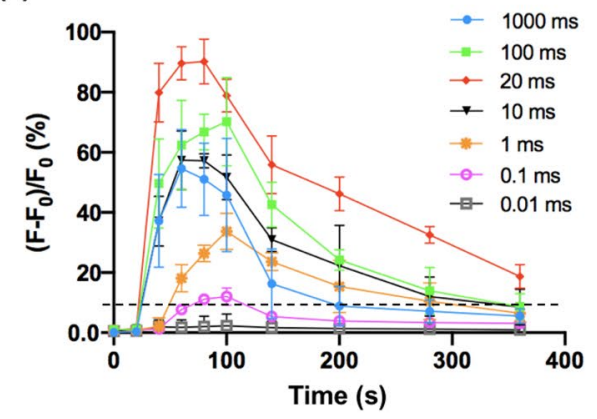

(d)

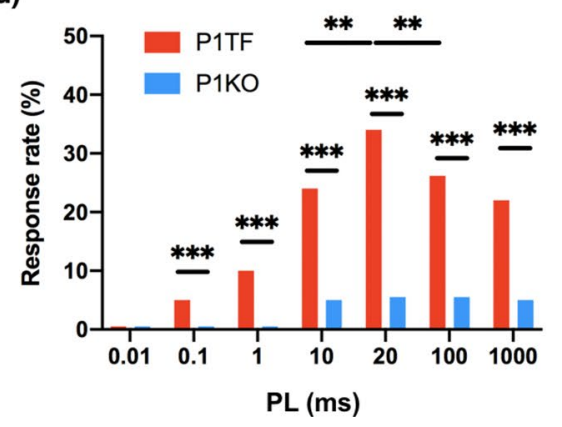

(b)

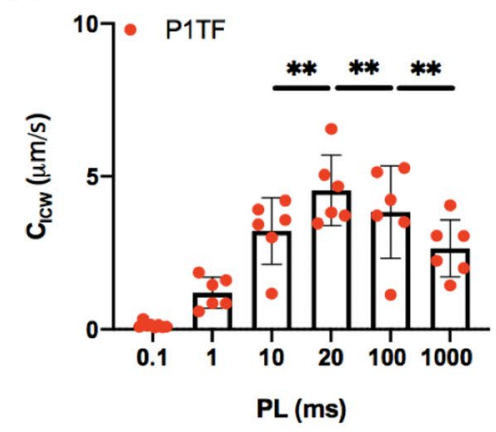

(e)

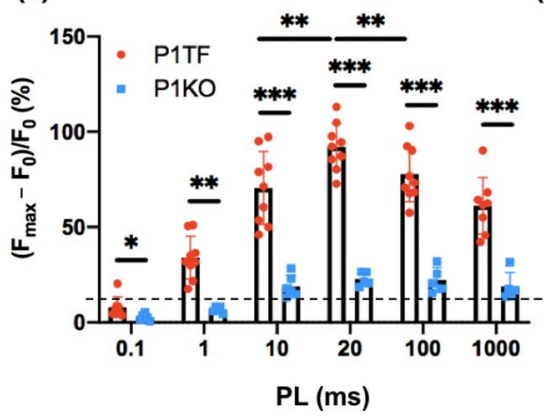

(c)

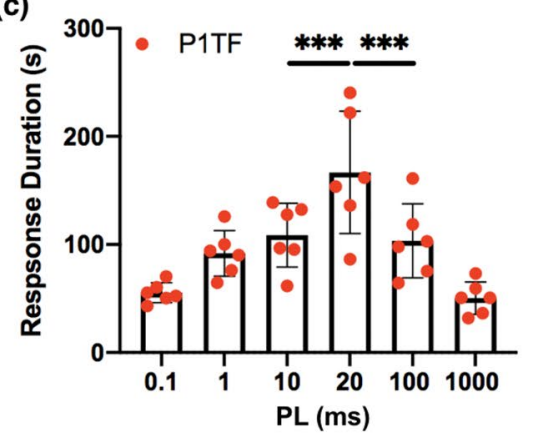

(f)

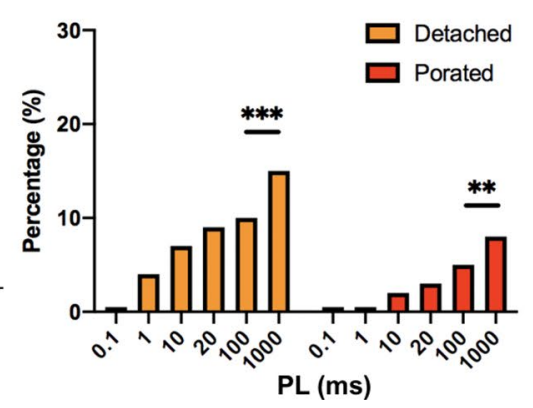

Figure 6. Piezol activation probability, $\left[\mathrm{Ca}^{2+}\right]_{i}$ characteristics, and the percentages of cell detached and membrane porated show a PL dependence at a constant shear stress level $\left(\tau=50\right.$ dyne $\left./ \mathrm{cm}^{2}\right)$. (a) The average temporal intracellular calcium ratio profile of P1TF cells in response to insonification at $\tau=50 \mathrm{dyne} / \mathrm{cm}^{2}$, $\mathrm{DC}=20 \%, \mathrm{TT}=60 \mathrm{~s}$ but different PL. $\mathrm{n}=6$ for each data point, error bars represent \pm std. (b) Intracellular calcium wave speed $\left(C_{I C W}\right)$ in P1TF cells at different PL $(n=6)$. (c) Response duration in P1TF cells at various PL $(n=6)$. (d) Response rate of P1TF and P1KO cells at various PL ( $\sim 20$ for each bar). (e) Peak normalized intracellular calcium ratio change in P1TF and P1KO cells at various PL ( $\mathrm{n} \sim 6$ for each case). Note: the data presented in (a) to (e) were based on cells that were neither detached nor porated following insonification. (f) Percentage of detached and porated cells over all the cells in the experiment at different PL. (total number of cells analyzed under each condition: $\mathrm{N} \sim 80)$. Two-tailed $\mathrm{t}$ test in $(\mathbf{b}),(\mathbf{c})$ and (e), Fisher's exact test in $(\mathbf{d})$ and (f). ${ }^{\star} \mathrm{p}<0.05,{ }^{\star *} \mathrm{p}<0.01,{ }^{* *} \mathrm{p}<0.001$, and 'ns' denotes not significant.

$\left[\mathrm{Ca}^{2+}\right]_{i}(93.5 \%)$ in the P1TF cells is about fourfold of the value (24.6\%) in the P1KO cells (Fig. 6e), indicating the much higher specificity and sensitivity of Piezol to shear compared to any other MS ion channels exist in the HEK293T cell membrane. In addition, the percentage of cell detachment and non-repairable membrane poration were found to increase monotonically with PL (Fig. 6f), presumably due to breakage of adhesive receptor-ligand bonds between the cell membrane and extracellular matrix ${ }^{38}$ and rupture of cell membrane under sustained shear with long stretch durations ${ }^{39}$. Therefore, prolonged increase in PL beyond $20 \mathrm{~ms}$ during insonification will result in higher risk of cell detachment and membrane poration without enhancing the $\mathrm{Ca}^{2+}$ response in the target cells.

Effects of US parameters on cell displacement (or deformation). The activation of Piezol is known to be directly linked with the cell membrane deformation produced under tension ${ }^{27}$. Yet, the individual and accumulated membrane deformation produced by different US pulsating protocols have not been thoroughly investigated. To ascertain the effects of US parameters on cell membrane deformation, we analyzed the displacement of the maximum fluorescent intensity $(380 \mathrm{~nm})$ point over the entire cytosol during insonification as a surrogate marker related to cell deformation using a previously developed protocol ${ }^{28}$.

Figures 7 shows representative results of cell displacement in response to different PLs produced at $\tau=50$ dyne $/ \mathrm{cm}^{2}$. Overall, the cell displacement (CD) vs. time curves showed a creep-recovery response characteristic of biological tissue and cells (i.e., viscoelastic soft materials) subjected to impulses of mechanical stress of constant amplitude $^{16,40}$. Much pronounced response was observed at PL $\geq 10 \mathrm{~ms}$ (Fig. 7a-d), which consisted of a rapid elastic deformation initiated at the onset of insonification $(20 \mathrm{~s})$, followed by a graduate viscoelastic response to reach the maximum cell displacement $\left(\mathrm{CD}_{\max }\right)$ during the insonification period. After the cessation of insonification ( $80 \mathrm{~s}$ ), the cell displayed instantaneously a small elastic recovery, followed by a gradual yet significant viscoelastic recovery with an exponential decay time constant on the order of 40 s. Even after 200 s, substantial residual (creep) displacement of the cell could still be observed. In contrast, at PL $\leq 1 \mathrm{~ms}$, weak and negligible response was observed (Fig. 7e,f). These results clearly demonstrate a PL dependent mechanical deformation of the cells during insonification. At the longest PL of $1000 \mathrm{~ms}$, which corresponds to an PRP = PL/DC (or interpulse time) of $5 \mathrm{~s}$, the creep-recovery response after each individual pulse could be resolved at the $10 \mathrm{fps}$ frame rate used for fluorescent imaging (see inset of Fig. 7a). As PL and thus interpulse time decreased, the viscoelastic response and recovery times would diminish significantly, leading to a much more rapid accumulation of the 


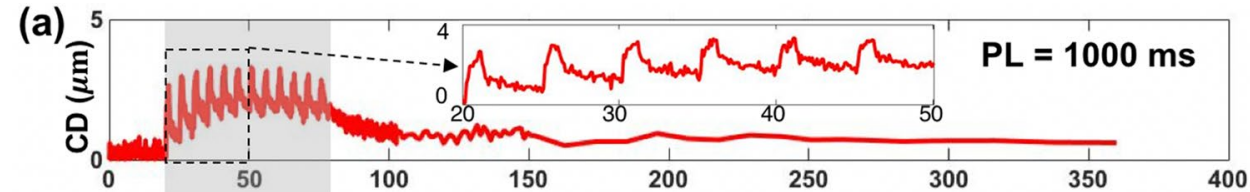

(b)

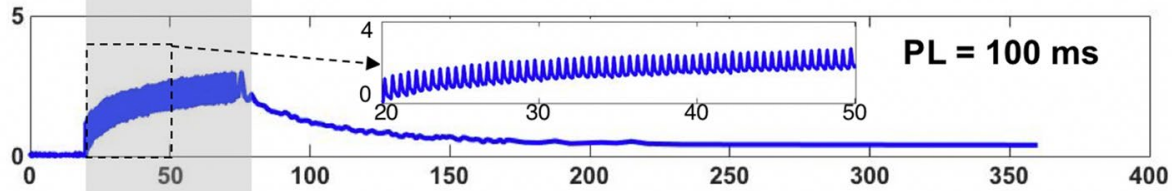

(c)

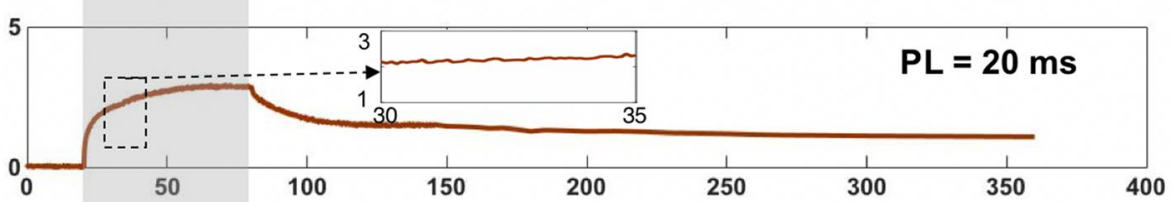

(d)

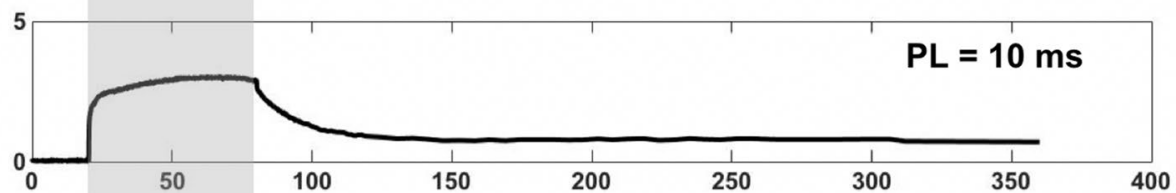

(e)

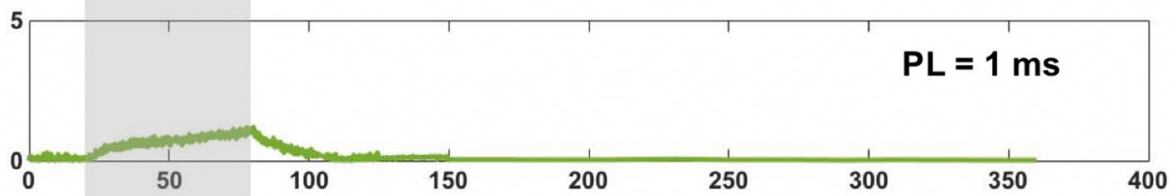

(f)

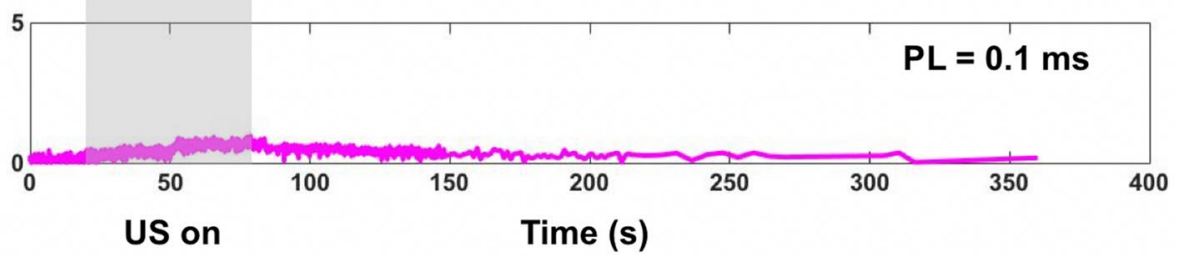

Figure 7. The time course of cell displacement (CD) shows distinct features at different PL, when $\tau=50$ dyne/ $\mathrm{cm}^{2}, \mathrm{DC}=20 \%, \mathrm{TT}=60 \mathrm{~s}$. (a) $\mathrm{PL}=1000 \mathrm{~ms}$. (b) $\mathrm{PL}=100 \mathrm{~ms}$. (c) $\mathrm{PL}=20 \mathrm{~ms}$. (d) $\mathrm{PL}=10 \mathrm{~ms}$. (e) $\mathrm{PL}=1 \mathrm{~ms}$. (f) $\mathrm{PL}=0.1 \mathrm{~ms}$. Gray rectangular indicate the time-window of insonification (20 s to $80 \mathrm{~s})$.

overall response, largely associated with the elastic deformation and recovery produced by individual pulses (see inset of Fig. 7b). At PL $=10 \sim 20 \mathrm{~ms}$, the accumulated CD during insonification reached the maximum with small oscillations between pulses associated with viscoelastic recovery. At further shortened PL $\leq 1 \mathrm{~ms}$, however, much weaker response with slow accumulations were produced despite the higher number of pulses generated under such insonification conditions.

Figure 8a illustrates the relationships between $\mathrm{CD}_{\max }$ and PL produced under $\tau=50 \mathrm{dyne} / \mathrm{cm}^{2}$. As PL increases, the average $C_{\max }$ will rise from 0.2 to $3.1 \mu \mathrm{m}$, reaching a peak at $\mathrm{PL}=20 \mathrm{~ms}$ before decaying slightly thereafter. Since cell deformation and resultant $\mathrm{Ca}^{2+}$ response to high strain-rate shear loading depend on both the amplitude and duration of the stimulation ${ }^{24,39}$, we further calculated the time integral of cell displacement square $\left(\mathrm{CDS}_{\mathrm{TI}}\right)$ produced by insonification, which is presumably proportional to the strain energy density impulse produced on the cell membrane ${ }^{39}$. As shown in Fig. $8 \mathrm{~b}, \mathrm{CDS}_{\mathrm{TI}}$ appears to reveal a biphasic dependence on PL with a distinct peak achieved at $20 \mathrm{~ms}$. At shorter PL, CDS $\mathrm{TI}_{\mathrm{TI}}$ increases progressively with PL. After reaching the maximum at $\mathrm{PL}=20 \mathrm{~ms}$ and at longer $\mathrm{PL}, \mathrm{CDS}_{\mathrm{TI}}$ will decrease at a different rate. In comparison to $\mathrm{CD}_{\max }$, the profile of $\mathrm{CDS}_{\mathrm{TI}}$ appears to better resemble the profiles in the responsive rate and peak $\left[\mathrm{Ca}^{2+}\right]_{i}$ ratio change of the P1TF cells at different PLs (Fig. 8c,d). Furthermore, among all the tests, the highest response rate with associated strongest $\left[\mathrm{Ca}^{2+}\right]_{i}$ increase was produced at $\mathrm{PL}=20 \mathrm{~ms}$ under $\tau=50 \mathrm{dyne} / \mathrm{cm}^{2}$, which is consistent with the peak in $\mathrm{CDS}_{\mathrm{TI}}$ In contrast, although the maximum $\mathrm{CD}_{\max }$ were produced at $\mathrm{PL}=100 \mathrm{~ms}$ under $\tau=74$ dyne/ $\mathrm{cm}^{2}$, lower than peak response rate and $\left[\mathrm{Ca}^{2+}\right]_{i}$ increase were observed, indicating that $\mathrm{CD}_{\max }$ alone is not reliable for predicting the $\left[\mathrm{Ca}^{2+}\right]_{i}$ response. Finally, it is important to note that $\mathrm{CDS}_{\mathrm{TI}}\left(125.4 \mathrm{~s} \mu \mathrm{m}^{2}\right)$ at $\mathrm{PL}=0.1 \mathrm{~ms}$ is significantly higher than the value $\left(35.4 \mathrm{~s} \mathrm{~mm}^{2}\right)$ at $\mathrm{PL}=0.01 \mathrm{~ms}$ under $\tau=50 \mathrm{dyne} / \mathrm{cm}^{2}$, and also higher than the corresponding value $\left(36.4 \mathrm{~s} \mathrm{\mu m}^{2}\right)$ at $\mathrm{PL}=100 \mathrm{~ms}$ under $18 \mathrm{dyne} / \mathrm{cm}^{2}$. These results suggest that a threshold in $\mathrm{CDS}_{\mathrm{TI}}\left(36.4 \mathrm{~s} \mu \mathrm{m}^{2} \cdot<\mathrm{CDS}_{\mathrm{TI}}<125.4 \mathrm{~s} \mu \mathrm{m}^{2}\right)$ is likely required to activate Piezol. Overall, our results confirm the important role of cell deformation in Piezol activation, and more importantly, suggesting that fine-tuning PL to match with the intrinsic viscoelastic properties of the cell may significantly improve the efficiency in ultrasonic activation of Piezo1. 

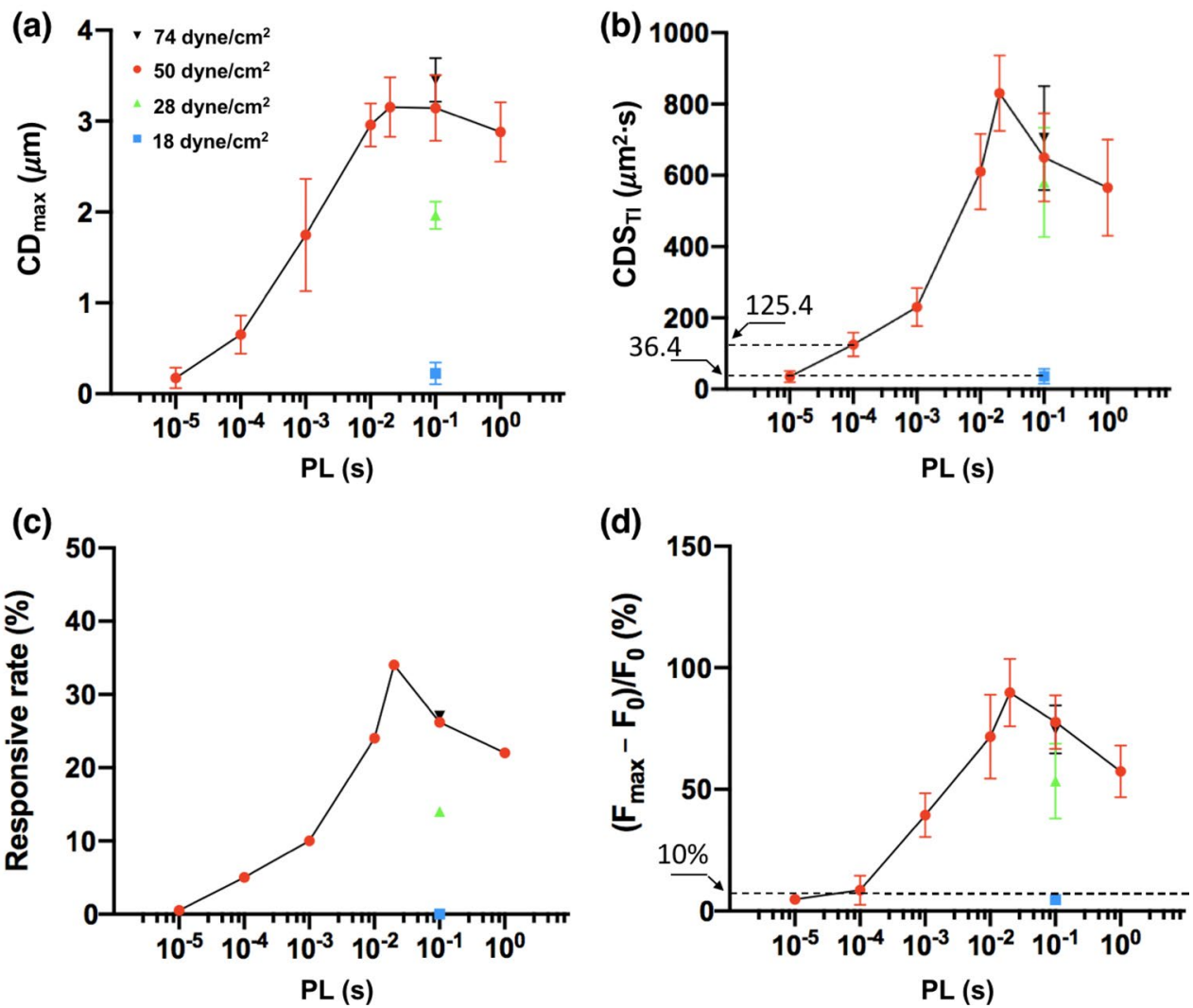

Figure 8. The time integral of cell displacement square $\left(\mathrm{CDS}_{\mathrm{TI}}\right)$ is a better predictor of the Piezol responsive rate and $\left[\mathrm{Ca}^{2+}\right]_{i}$ uptake, compared to $\mathrm{CD}_{\max }$. (a) Maximum cell displacement $\left(\mathrm{CD}_{\max }\right)$ during the insonification at different PL and $\tau . \mathrm{n}=6$ for each condition. (b) Time integral of cell displacement square $\left(\mathrm{CDS}_{\mathrm{TI}}\right)$ during the insonification at different PL and $\tau . \mathrm{n}=6$ for each condition. (c) Responsive rate of P1TF cells at different PL and $\tau$. (d) Peak normalized intracellular calcium ratio at different PL from $0.01 \mathrm{~ms}$ to $1000 \mathrm{~ms}$ and under various $\tau$ levels: $18 \mathrm{dyne} / \mathrm{cm}^{2}$ (blue square), $28 \mathrm{dyne} / \mathrm{cm}^{2}$ (green upward triangle), $50 \mathrm{dyne} / \mathrm{cm}^{2}$ (red circles) and $74 \mathrm{dyne} /$ $\mathrm{cm}^{2}$ (black downward triangle). $\mathrm{n}=6$ for each condition.

Numerical modeling of four-state channel gating dynamics of Piezo1 in relation to PL-dependent $\left[\mathrm{Ca}^{2+}\right]_{i}$ response. To facilitate data interpretation from the experiments, we have adapted a four-state model for channel gating of Piezo1 constructed based on electrophysiology measurements ${ }^{27}$. Especially, the model can be used to reveal the intricate dynamic interactions between the open $(\mathrm{O})$, closed $(\mathrm{C})$ and two inactivation $\left(\mathrm{I}_{1}\right.$ and $\mathrm{I}_{2}$ ) states of the Piezo1 channel under dynamic loading that determines its overall frequency response (Fig. 9a). Most importantly, previous studies ${ }^{27}$ have uncovered two kinetically distinct inactivation (i.e., non-conducting despite continued presence of membrane tension) states of Piezo1 with drastically different current recovery time constants ( $24 \mathrm{~ms}$ for $\mathrm{I}_{1}$ and $10 \mathrm{~s}$ for $\mathrm{I}_{2}$ ). As a result, Piezol-mediated current influx may rise rapidly $(\sim \mathrm{ms})$ in response to membrane tension and then decay exponentially over a much longer timescale due to inactivation ${ }^{17}$. Because of inactivation, Piezo1 will respond strongly to the first (or onset of the) stimulus when subjected to repetitive membrane tension, and gradually become desensitized in a frequency filtering process highly modulated by the waveform and PRF of the stimulus ${ }^{27}$. Since Piezol exhibits cationic nonselective permeability ${ }^{17}$, we hypothesize that the inactivation of Piezol may affect the $\mathrm{Ca}^{2+}$ influx induced by US pulses in a PL-dependent manner.

In the original four-state gating model, the transition rates $a(\tau)$ and e $(\tau)$ were assumed to be modulated by the amplitude of the micropipette pressure applied to the plasma membrane (or equivalently shear stress in this study). Other transition rates in the model were constants, which were determined by numerical fitting of the experimental data in response to $2-20 \mathrm{~Hz}$ stimuli. However, we found that the original four-state model is insufficient for capturing the trend in the time-integral of the evoked current (Supplementary Fig. S8c). To overcome this limitation, we further assume that the transition rates between $\mathrm{O}$ and $\mathrm{I}_{2}(g$ and $h)$ are PL dependent (see Eqs. S1 and S2 in SI) while keeping all the other parameters unchanged. This modified four-state model has been shown to capture well both the transient and integrated features of Piezol kinetics (Supplementary Fig. S8b,c).

The general features of Piezo1 have been recapitulated under the insonification conditions evaluated in this study. Figure 9 shows the time course of the response probability of the four states $\left(\mathrm{O}, \mathrm{C}, \mathrm{I}_{1}\right.$ and $\left.\mathrm{I}_{2}\right)$ of the Piezo 1 channels on the cell membrane during insonification for $\mathrm{PL}=1,20$ and $1000 \mathrm{~ms}$. Assuming constant $\tau$ (or membrane tension) during each pulse, the model simulation suggests that the Piezol channel open probability will increase rapidly to the maximum during the "on time" of the first pulse, and then decay exponentially in the "off 
(a)

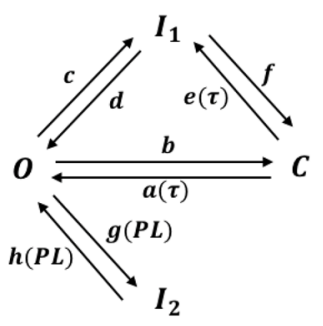

(b)

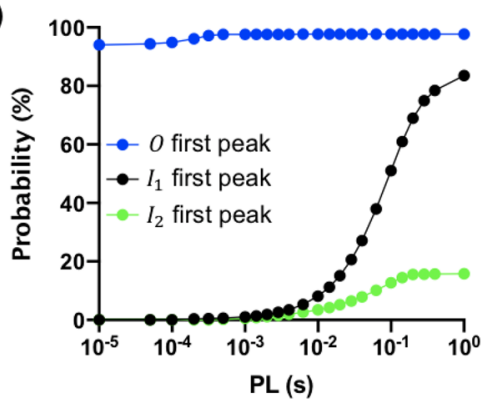

(c)

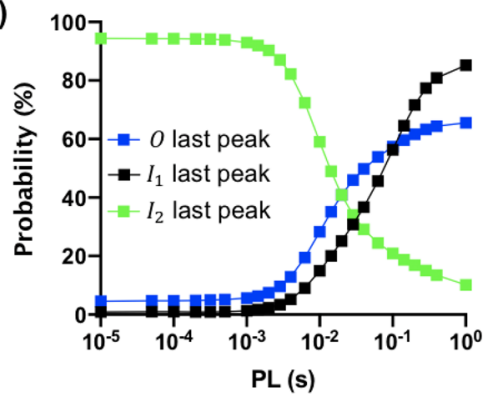

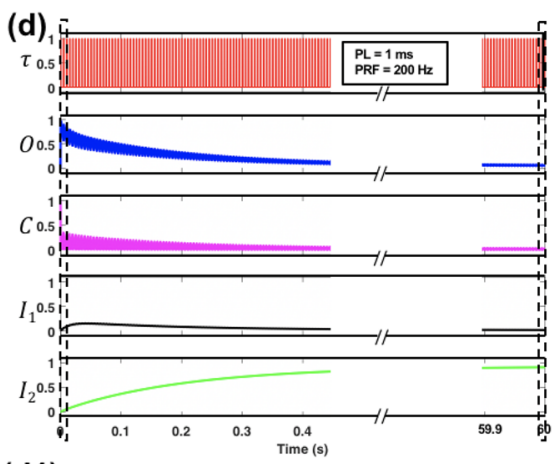

(d1)

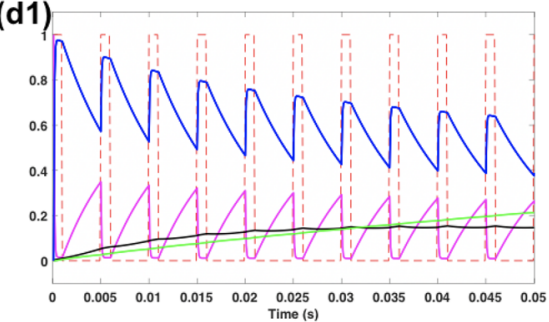

(d2)

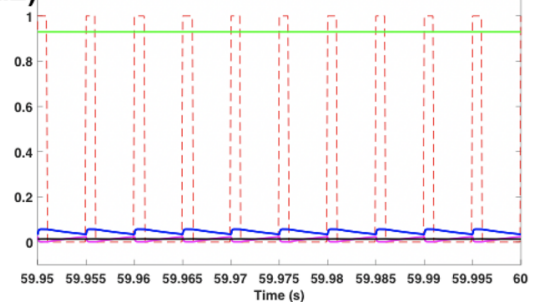

(e)

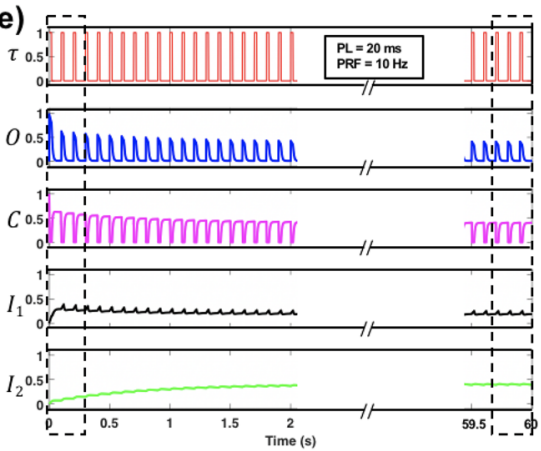

(e1)

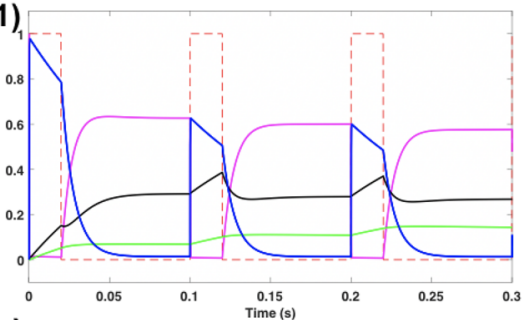

(e2)

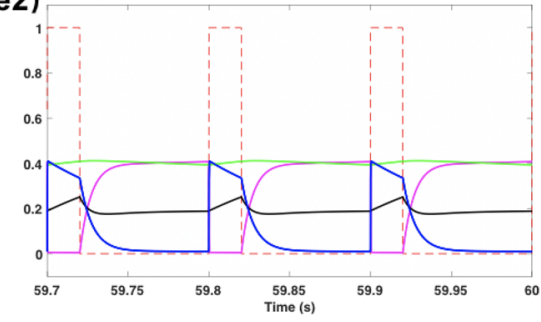

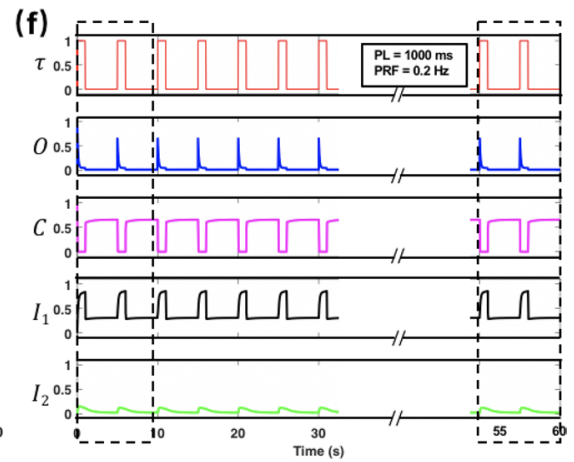

(f1)

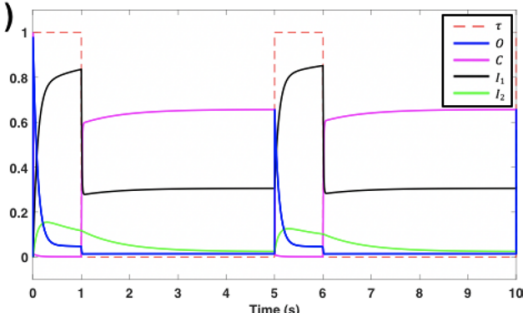

(f2)

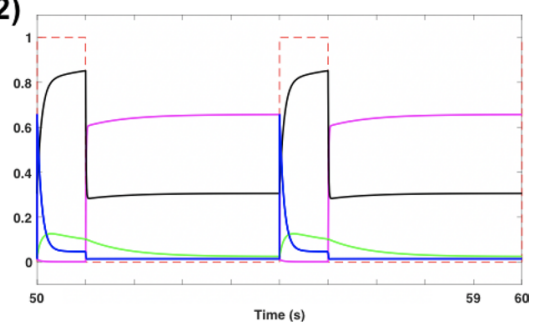

Figure 9. Simulation of Piezol channel kinetics by the modified four-state gating model. (a) A schematic of the modified four-state gating mechanism for Piezol, with arrows indicating transitions between open $(\mathrm{O})$, closed $(\mathrm{C})$ and two inactivated states $\left(\mathrm{I}_{1}\right.$ and $\left.\mathrm{I}_{2}\right)$. In the original model, $a(\tau)$ ande $(\tau)$ are coupling coefficients between $\mathrm{C}, \mathrm{O}$ and $\mathrm{I}_{1}$ states, respectively, which are modulated by the pressure (or equivalently $\tau$ in this study) applied to the plasma membrane, leading to membrane tension. Moreover, $g$ and $h$ are the coupling coefficients between $\mathrm{O}$ and $\mathrm{I}_{2}$ states, which are constants. In the modified model, $g(P L)$ and $h(P L)$ are assumed to be PL-dependent while the rest of the coefficients are the same as in the original model. (b) The peak probability of the $\mathrm{O}, \mathrm{I}_{1}$ and $\mathrm{I}_{2}$ evoked by the $1^{\text {st }}$ pulse at various PL. (c) The peak probability of the $\mathrm{O}, \mathrm{I}_{1}$ and $\mathrm{I}_{2}$ evoked by the last pulse at various PL. (d-f) The normalized shear stress (red), simulated Piezo1 open (blue), closed (magenta), inactivation 1 (black) and inactivation 2 (green) probabilities change in response to $60 \mathrm{~s}$ insonification for $\mathrm{PL}=1,20$ and $1000 \mathrm{~ms}$, respectively. (d1-f1) The magnified plot at the beginning of the insonification for $\mathrm{PL}=1$, 20 and $1000 \mathrm{~ms}$, respectively. (d2-f2) The magnified plot toward the end of the insonification for PL=1,20 and $1000 \mathrm{~ms}$, respectively.

time" of the US. Such a process is repeated following each of the subsequent pulses, leading to a progressively decayed response during the entire insonification process. The change in the Piezol channel "open" probability is accompanied by an inversely varied "closed" probability, and further modulated concomitantly by the two "inactivation" states. In particular, the time profiles of the four states were found to be highly sensitive to PL. At short PL (=1 ms), the probability of $\mathrm{O}$ increases quickly to the maximum peak (98\%) near the end of the first pulse while the probability of $\mathrm{I}_{1}$ only elevates incrementally, reaching the maximum (16\%) after about ten pulses before decaying slowly to the ground level toward the end of insonification. More interestingly, the probability of $\mathrm{I}_{2}$ increases progressively and accumulates significantly during the 12,000 pulses, reaching the maximum $(90 \%)$ near the end of the insonification to desensitize most of the Piezol channels. Therefore, the significant 


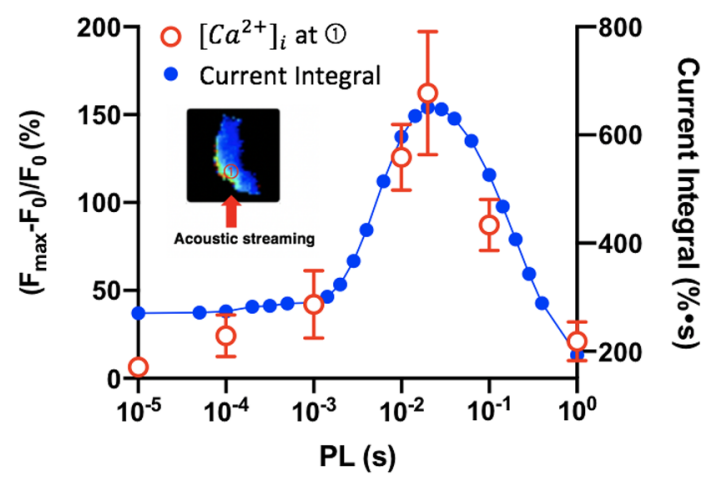

Figure 10. Correlation of the simulated current integral with the experimentally measured $\mathrm{Ca}^{2+}$ influx at the initiation site. Red open circles: peak normalized $\left[\mathrm{Ca}^{2+}\right]_{i}$ peak change near the cell boundary at region (1) in experiment ( $\mathrm{n} \sim 6$ at each PL). Blue closed circles: simulated time-integral of current obtained by the modified four-state model.

and predominant rise in $\mathrm{I}_{2}$ limits the $\mathrm{Ca}^{2+}$ response elicited by short PL. In contrast, at long PL (= $\left.1000 \mathrm{~ms}\right)$, the probability of $\mathrm{O}$ increases instantaneously at the beginning of the first pulse to the maximum peak (98\%) and then decays quickly to near ground level $(<3 \%)$ before the cessation of the pulse. During this period, both $\mathrm{I}_{1}$ and $\mathrm{I}_{2}$ are evoked fully to reach their corresponding peaks of $82 \%$ and $16 \%$, respectively. In the ensuing long interpulse time $(4000 \mathrm{~ms})$, the levels of $\mathrm{I}_{1}$ and $\mathrm{I}_{2}$ will decrease yet still maintaining between 5 to $25 \%$. As a result, the probability of $\mathrm{O}$ evoked by the subsequent pulses will drop below $65 \%$ and reminds fairly constant during the insonification process. The inefficient opening during each pulse, combined with the limited total number of pulses (12) during insonification lead to low $\mathrm{Ca}^{2+}$ response produced by long PL. At the optimal PL $=20 \mathrm{~ms}$, the probability of $\mathrm{O}$ expands the full pulse length while the levels of $\mathrm{I}_{1}$ and $\mathrm{I}_{2}$ are kept below $50 \%$ during the insonification process. The combination of efficient opening during each pulse with a modest decay of the peak opening rate and sufficiently large number of pulses (600) during the insonification produces a strong $\mathrm{Ca}^{2+}$ response.

To compare with the $\left[\mathrm{Ca}^{2+}\right]_{i}$ change observed in the experiment, we plot the current integral on the cell membrane under tension during insonification calculated by the modified four-state model for different PLs. To match with the model simulation with minimal influence of CICR in the cytosol, we analyzed the $\left[\mathrm{Ca}^{2+}\right]_{i}$ ratio change near the cell boundary in region (1) of each cell where the calcium response was initiated (Figs. 3, 5). As shown in Fig. 10, the simulation results demonstrate a similar biphasic dependency on PL with a peak achieved at $\mathrm{PL}=20 \mathrm{~ms}$, as observed from the experiments. This reasonably good agreement between modeling prediction and experimental measurement further supports the notion that inactivation states of Piezol play an important role in shaping its optimal response condition to US simulation.

\section{Discussion}

Sonogenetics represents a promising approach for non-invasive and selective activation of target cells in the body that are genetically modified to overexpress a specific MS ion channel ${ }^{23}$. A critical step in successful sonogenetics applications is to determine the appropriate insonification conditions that are most effective for activating the target MS ion channel while minimizing adverse effects. In this study, we utilized a novel VD-SAW platform to investigate the optimal insonification parameters for Piezol activation and $\left[\mathrm{Ca}^{2+}\right]_{i}$ response in HEK293T cells transfected with Piezo1. Under the same insonification DC, total acoustic energy and treatment time $(60 \mathrm{~s})$, we have discovered that Piezol activation depends critically on PL, with a distinct peak produced at PL $=20 \mathrm{~ms}$ under a constant shear stress of 50 dyne $/ \mathrm{cm}^{2}$ (i.e., the highest Piezol activation probability with associated strongest $\left[\mathrm{Ca}^{2+}\right]_{i}$ response at $<10 \%$ cell detachment or membrane injury).

In general, multiple factors at three different levels may contribute to the PL-dependency in Piezol activation by US. First, the transmission and penetration depth of US in the body are frequency dependent and the resultant tissue deformation (produced either by acoustic radiation force or shear) will be influenced by the acoustic and viscoelastic properties of the interposing tissues between the US transducer and the target organ ${ }^{41-43}$. Even at the superficial skin level, the mechanical filtering effects of the tissue to insonification have been demonstrated, for example, in the touch receptor neurons in C. elegans ${ }^{40}$. Second, in the target tissue, the response to insonification at the cellular level will be influenced by the viscoelastic properties of the cytoskeleton and plasma membrane. Actin filaments, microtubules, and intermediate filaments in the cytoskeleton form an adaptive network that can resist stress-induced deformation in order to protect the intracellular compartments ${ }^{44}$. Similarly, the lipid bilayer of the plasma membrane is also known to have its own distinct viscoelasticity properties ${ }^{45}$, which influence lipid-protein or protein-protein interaction-induced cell signaling across the membrane surface ${ }^{46}$. Altogether, the convolution of the viscoelastic properties of the tissues and target cells will impose a time-dependent filtering effect on the mechanical forces delivered by the US pulses. As a result, only a narrow range of the PL (determined by the combination of DC and PRF) around the peak region of the viscoelastic response spectrum of the tissuecell complex may be used to produce effective deformation and thus eliciting a robust calcium response in the target cell during insonification without causing significant adverse effects (e.g., over-heating of the interposed tissues or injuring the target cells). In this study, such a PL-dependency in cell deformation is exemplified by the 
time-integral of cell displacement square $\left(\mathrm{CDS}_{\mathrm{TI}}\right)$, which shows a biphasic relationship with $\mathrm{PL}$, and correlating with the Piezol activation probability and $\left[\mathrm{Ca}^{2+}\right]_{i}$ response (see Fig. 8).

Beyond the filtering effects of tissues and cells, a third level of factors that can critically influence the calcium (and thus neural) response of the target cell to insonification is the kinetics of the MS ion channels on the plasma membrane under mechanical deformation. Such a factor was not examined in previous sonogenetics studies ${ }^{18,23}$. In comparison, recent patch-clamp electrophysiology studies have demonstrated the importance of inactivation of Piezo1 and other MS ion channels in modulating cellular physiology ${ }^{17}, 27$. In the previous electrophysiology studies, however, PL was fixed at $30 \mathrm{~ms}$ while the PRF was varied from 0.5 to $50 \mathrm{~Hz}$, leading to different DC and total mechanical energy applied to the cell membrane ${ }^{27}$. In this work, we kept the DC, TT and thus the total acoustical energy delivered to the target cells constant to order to determine the optimal PL for safe and effective activation of Piezo1. The experimental observations were supported by the simulation results from the modified four-state model for Piezol channel gating, further reinforcing the idea that optimal US protocols could be developed in sonogenetics based on the characteristics of the target MS channels determined by their intrinsic structures ${ }^{47}$.

Moreover, our results suggest that the viscoelastic properties of the target cell are also important factors that will influence the mechanical response (see Fig. 7), and consequently, the resultant membrane tension that leads to Piezol activation. The coincident overlap in the peak of $\mathrm{CDS}_{\mathrm{TI}}$ (Fig. 8b) and the model-predicted current integral of Piezol (Fig. 10) further accentuate the distinct maximum $\left[\mathrm{Ca}^{2+}\right]_{i}$ response observed under PL $=20 \mathrm{~ms}$. Conceptually, it is possible that the peaks for cell deformation and MS ion channel activation are generally achieved at different PLs, which would broaden the range of insonification conditions for neuromodulation yet with potentially reduced specificity and sensitivity.

In summary, we have demonstrated that PL is a critical parameter in ultrasonic activation of Piezol and resultant intracellular calcium response. By producing impulsive yet sufficiently sustained cell deformation using acoustic streaming-generated shear stresses, the Piezol ion channels embedded in the cell membrane could be opened. The effectiveness of Piezol activation is not achieved by rapidity of the stimuli or high number of repetitions using short PL (see also Supplementary Fig. S9) or high PRF for a fixed DC. Neither would it be achieved using long PL or low PRF without prolonging treatment time or increasing the risk of injury. For the same acoustic energy delivered to the target cells, therefore, the shear stress amplitude and PL of the insonification need to be optimized to achieve safe and efficient activation of Piezol based on the accumulated effects of adequate yet not excessive membrane deformation. The knowledge gained in this study has significant implications to sonogenetics applications, in which the PL of US should be carefully selected based on the properties of target tissue, cell and MS ion channels. Altogether, our work underscores the importance of fine-tuning the stimulus parameters to maximize the safety and efficacy of US neuromodulation strategies for noninvasive treatment of various neurological disorders.

\section{Methods}

Cell culture and transfection. HEK293T-P1KO cells (Piezo1 knock-out human embryonic kidney cells) and plasmid Mouse Piezo1-pIRES-EGFP in pcDNA3.1 were obtained from Dr. Jorg Grandl of Duke Neurobiology and previously described ${ }^{48}$. Cells were cultured in a 6-well plate in DMEM (high glucose) supplemented with $10 \%$ heat-inactivated fetal bovine serum (FBS) and penicillin/streptomycin antibiotics (DMEM complete medium), and grown in a cell culture incubator at $37^{\circ} \mathrm{C}$ with $5 \% \mathrm{CO}_{2}$ as previously described ${ }^{17}$. Cells were transiently transfected with Mouse Piezol $(3 \mu \mathrm{g})$ in the presence of $10 \mu \mathrm{M}$ ruthenium red using Fugene6 (Promega, Madison, WI) according to manufacturer protocol. About $20-30 \%$ of cells showed positive GFP expression indicating successful transfection of Piezo1 and were considered as P1TF cells. After 2 days, cells were reseeded in a $35 \mathrm{~mm}$ glass-bottomed Petri dish (81158, ibidi), which was coated with $50 \mu \mathrm{g} / \mathrm{mL}$ Fibronectin (ThermoFisher Scientific). Cells were then incubated in DMEM complete medium at $37^{\circ} \mathrm{C}$ for $3 \mathrm{~h}$ before US treatment.

VD-SAW transducer. A focused, 20-finger pair interdigital transducer (IDT) SAW device with aperture size $(12 \times 8 \mathrm{~mm})$ was used to generate ultrasound pulses in the form of leaky pressure waves. The width of each finger and the gap between two adjacent fingers were set as $\lambda / 4=32.5 \mu \mathrm{m}$ to define the SAW wavelength at $\lambda=130 \mu \mathrm{m}$. The fingers were designed as a series of concentric-circular arcs with a $40^{\circ}$ open angle to produce a focused acoustic filed. A $0.5-\mathrm{mm}$ thick, $128^{\circ}-\mathrm{Y}$ cut LiNiO3 wafer (Precision Micro-Optics) was used as the substrate. A double-layer metal $(90 \mathrm{~nm} \mathrm{Au}$ and $10 \mathrm{~nm} \mathrm{Cr}$ ) was subsequently deposited on the wafer using an e-beam evaporator (CHA solution), followed by a lift-off process to remove the photoresist and form the IDT. The fundamental frequency of IDT (33 MHz) was determined by a network analyzer prior to operation. Sinusoidal signals with pulse modulation were produced by a signal generator (Model 4065, B\&K Precision), amplified by a $55 \mathrm{~dB}$ RF amplifier (Model A150, ENI), then applied to the IDT.

Fluorescence and bright field imaging. Fluorescence and bright field imaging systems were incorporated in the VD-SAW platform to monitor the intracellular $\mathrm{Ca}^{2+}$ signaling and characterize the morphological change of the cells produced by insonification. Intracellular calcium response $\left(\left[\mathrm{Ca}^{2+}\right]_{i}\right)$ was measured by fluorescence imaging using the indicator dye fura- $2 \mathrm{AM}^{49}$. After incubation, the Petri dish was washed 3 times with OptiMEM to eliminate the excess fura-2 AM before insonification. $100 \mu \mathrm{g} / \mathrm{mL}$ propidium iodide (PI) was added to monitor membrane permeability change and cell necrosis ${ }^{24}$. A monochromator (DELTARAM X; PTI) was used for calcium and PI imaging. $\left[\mathrm{Ca}^{2+}\right]_{i}$ was measured by ratiometric imaging with fura-2 at 340 and $380 \mathrm{~nm}$ excitation, and the fluorescence emission was recorded at $510 \mathrm{~nm}$ by a sCMOS camera (EDGE 5.5 CL; PCO) at a frame rate of $10 \mathrm{~Hz}$ for a total recording time up to $350 \mathrm{~s}$ as described previously ${ }^{28}$. Thereafter, the ratio between 
fluorescence intensity from 340 and $380 \mathrm{~nm}$ excitation (F) over time was obtained in the EasyRatioPro 2 imaging processing software (HORIBA Scientific).

Data analysis. The normalized fluorescence ratio change $\left[\left(F-F_{0}\right) / F_{0}\right]$, where $F_{0}$ is the average resting value of the cell before US treatment, was further analyzed using MATLAB (MathWorks) to obtain the characteristics of $\left[\mathrm{Ca}^{2+}\right]_{-i}$ (peak amplitude and response time) $)^{28}$. The response time is defined as the full-width at half maximum of the $\left[\mathrm{Ca}^{2+}\right]_{i}$ response. At high input voltage (or shear stress), cells might move along the acoustic streaming direction during insonification, leading to some fluorescence intensity fluctuations, up to $10 \%$ of the resting value. Thus, only the cells with the peak normalized ratio change greater than $10 \%$ were considered as "responsive" above the background noise level ${ }^{28}$. The intracellular calcium wave (ICW) speed was calculated based on the protocol previously described ${ }^{24}$. Two circular regions ( $5 \mu \mathrm{m}$ in diameter), with region 1 located at the area where $\left[\mathrm{Ca}^{2+}\right]_{i}$ initiated and region 2 near the center of the cell, were drawn manually by the ROI manager in ImageJ. The time delay of the half maximum of $\left[\mathrm{Ca}^{2+}\right]_{i}$ response at these two regions were used as the $\left[\mathrm{Ca}^{2+}\right]_{i}$ propagating time. The peak $\left[\mathrm{Ca}^{2+}\right]_{i}$ change at region 1 was further used as a measure of the $\mathrm{Ca}^{2+}$ influx mediated by Piezo1 in P1TF cells.

Received: 29 August 2020; Accepted: 19 November 2020

Published online: 12 January 2021

\section{References}

1. Foster, K. R. \& Wiederhold, M. L. Auditory responses in cats produced by pulsed ultrasound. J. Acoust. Soc. Am. 63, 1199-1205. https://doi.org/10.1121/1.381829(1978).

2. Gavrilov, L. R., Tsirulnikov, E. M. \& Davies, I. A. Application of focused ultrasound for the stimulation of neural structures. Ultrasound. Med. Biol. 22, 179-192. https://doi.org/10.1016/0301-5629(96)83782-3 (1996).

3. Tufail, Y., Yoshihiro, A., Pati, S., Li, M. M. \& Tyler, W. J. Ultrasonic neuromodulation by brain stimulation with transcranial ultrasound. Nat. Protoc. 6, 1453-1470. https://doi.org/10.1038/nprot.2011.371 (2011).

4. Yoo, S. S. et al. Focused ultrasound modulates region-specific brain activity. Neuroimage 56, 1267-1275. https://doi.org/10.1016/j. neuroimage.2011.02.058 (2011).

5. Deffieux, T. et al. Low-intensity focused ultrasound modulates monkey visuomotor behavior. Curr. Biol. 23, 2430-2433. https:// doi.org/10.1016/j.cub.2013.10.029 (2013).

6. Menz, M. D., Oralkan, O., Khuri-Yakub, P. T. \& Baccus, S. A. Precise neural stimulation in the retina using focused ultrasound. J. Neurosci. 33, 4550-4560. https://doi.org/10.1523/JNEUROSCI.3521-12.2013 (2013).

7. Mihran, R. T., Barnes, F. S. \& Wachtel, H. Temporally-specific modification of myelinated axon excitability in vitro following a single ultrasound pulse. Ultrasound. Med. Biol. 16, 297-309. https://doi.org/10.1016/0301-5629(90)90008-z (1990).

8. Tsui, P. H., Wang, S. H. \& Huang, C. C. In vitro effects of ultrasound with different energies on the conduction properties of neural tissue. Ultrasonics 43, 560-565. https://doi.org/10.1016/j.ultras.2004.12.003 (2005).

9. Colucci, V., Strichartz, G., Jolesz, F., Vykhodtseva, N. \& Hynynen, K. Focused ultrasound effects on nerve action potential in vitro. Ultrasound. Med. Biol. 35, 1737-1747. https://doi.org/10.1016/j.ultrasmedbio.2009.05.002 (2009).

10. Leinenga, G., Langton, C., Nisbet, R. \& Gotz, J. Ultrasound treatment of neurological diseases-current and emerging applications. Nat. Rev. Neurol. 12, 161-174. https://doi.org/10.1038/nrneurol.2016.13 (2016).

11. Fomenko, A., Neudorfer, C., Dallapiazza, R. F., Kalia, S. K. \& Lozano, A. M. Low-intensity ultrasound neuromodulation: An overview of mechanisms and emerging human applications. Brain Stimul. 11, 1209-1217. https://doi.org/10.1016/j.brs.2018.08.013 (2018).

12. Blackmore, J., Shrivastava, S., Sallet, J., Butler, C. R. \& Cleveland, R. O. Ultrasound neuromodulation: a review of results, mechanism and safety. Ultrasound. Med. Biol. 45, 1509-1536. https://doi.org/10.1016/j.ultrasmedbio.2018.12.015 (2019).

13. Bystritsky, A. et al. A review of low-intensity focused ultrasound pulsation. Brain Stimul. 4, 125-136. https://doi.org/10.1016/j. brs.2011.03.007 (2011).

14. King, R. L., Brown, J. R., Newsome, W. T. \& Pauly, K. B. Effective parameters for ultrasound-induced in vivo neurostimulation. Ultrasound. Med. Biol. 39, 312-331. https://doi.org/10.1016/j.ultrasmedbio.2012.09.009 (2013).

15. Kim, H. et al. Noninvasive transcranial stimulation of rat abducens nerve by focused ultrasound. Ultrasound. Med. Biol. 38, 1568-1575. https://doi.org/10.1016/j.ultrasmedbio.2012.04.023 (2012).

16. Kubanek, J., Shukla, P., Das, A., Baccus, S. A. \& Goodman, M. B. Ultrasound elicits behavioral responses through mechanical effects on neurons and ion channels in a simple nervous system. J. Neurosci. 38, 3081-3091. https://doi.org/10.1523/JNEUROSCI.145817.2018 (2018).

17. Coste, B. et al. Piezo1 and Piezo2 are essential components of distinct mechanically activated cation channels. Science 330, 55-60. https://doi.org/10.1126/science.1193270 (2010).

18. Pan, Y. et al. Mechanogenetics for the remote and noninvasive control of cancer immunotherapy. Proc. Natl. Acad. Sci. USA 115, 992-997. https://doi.org/10.1073/pnas.1714900115 (2018).

19. Prieto, M. L., Firouzi, K., Khuri-Yakub, B. T. \& Maduke, M. Activation of Piezo1 but Not NaV1.2 channels by ultrasound at 43 MHz. Ultrasound. Med. Biol. 44, 1217-1232. https://doi.org/10.1016/j.ultrasmedbio.2017.12.020 (2018).

20. Qiu, Z. et al. The mechanosensitive ion channel piezol significantly mediates in vitro ultrasonic stimulation of neurons. iScience 21, 448-457 (2019).

21. Kubanek, J. et al. Ultrasound modulates ion channel currents. Sci. Rep. 6, 24170. https://doi.org/10.1038/srep24170 (2016).

22. Tyler, W. J. et al. Remote excitation of neuronal circuits using low-intensity, low-frequency ultrasound. PLoS ONE 3, e3511. https ://doi.org/10.1371/journal.pone.0003511 (2008).

23. Ibsen, S., Tong, A., Schutt, C., Esener, S. \& Chalasani, S. H. Sonogenetics is a non-invasive approach to activating neurons in Caenorhabditis elegans. Nat. Commun. 6, 8264. https://doi.org/10.1038/ncomms9264 (2015).

24. Li, F. et al. Dynamics and mechanisms of intracellular calcium waves elicited by tandem bubble-induced jetting flow. Proc. Natl. Acad. Sci. USA 115, E353-E362. https://doi.org/10.1073/pnas.1713905115 (2018).

25. Wu, J., Lewis, A. H. \& Grandl, J. Touch, tension, and transduction - the function and regulation of piezo ion channels. Trends Biochem. Sci. 42, 57-71. https://doi.org/10.1016/j.tibs.2016.09.004 (2017).

26. Lewis, A. H. \& Grandl, J. Mechanical sensitivity of Piezol ion channels can be tuned by cellular membrane tension. Elife 4, 1. https ://doi.org/10.7554/eLife.12088 (2015). 
27. Lewis, A. H., Cui, A. F., McDonald, M. F. \& Grandl, J. Transduction of repetitive mechanical stimuli by Piezo1 and Piezo2 ion channels. Cell Rep. 19, 2572-2585. https://doi.org/10.1016/j.celrep.2017.05.079 (2017).

28. Liao, D., Li, F., Lu, D. \& Zhong, P. Activation of Piezo1 mechanosensitive ion channel in HEK293T cells by $30 \mathrm{MHz}$ vertically deployed surface acoustic waves. Biochem. Biophys. Res. Commun. 518, 541-547. https://doi.org/10.1016/j.bbrc.2019.08.078 (2019).

29. Ranade, S. S. et al. Piezo1, a mechanically activated ion channel, is required for vascular development in mice. Proc. Natl. Acad. Sci. USA 111, 10347-10352. https://doi.org/10.1073/pnas.1409233111 (2014).

30. Maneshi, M. M., Ziegler, L., Sachs, F., Hua, S. Z. \& Gottlieb, P. A. Enantiomeric Abeta peptides inhibit the fluid shear stress response of PIEZO1. Sci. Rep. 8, 14267. https://doi.org/10.1038/s41598-018-32572-2 (2018).

31. Lai, A. et al. Analyzing the shear-induced sensitization of mechanosensitive ion channel Piezo-1 in human aortic endothelial cells. J. Cell Physiol. 1, 12. https://doi.org/10.1002/jcp.30056 (2020).

32. Jetta, D., Gottlieb, P. A., Verma, D., Sachs, F. \& Hua, S. Z. Shear stress-induced nuclear shrinkage through activation of Piezo1 channels in epithelial cells. J. Cell Sci. 132, 11. https://doi.org/10.1242/jcs.226076 (2019).

33. Reed, J. et al. High throughput cell nanomechanics with mechanical imaging interferometry. Nanotechnology 19, 235101. https:// doi.org/10.1088/0957-4484/19/23/235101 (2008).

34. Cox, C. D. et al. Removal of the mechanoprotective influence of the cytoskeleton reveals PIEZO1 is gated by bilayer tension. Nat. Commun. 7, 10366. https://doi.org/10.1038/ncomms10366 (2016).

35. Syeda, R. et al. Piezol channels are inherently mechanosensitive. Cell Rep. 17, 1739-1746. https://doi.org/10.1016/j.celre p.2016.10.033 (2016)

36. Stamp, M. E. et al. Exploring the limits of cell adhesion under shear stress within physiological conditions and beyond on a chip. Diagnostics 6, 38. https://doi.org/10.3390/diagnostics6040038 (2016).

37. Jaffe, L. F. Classes and mechanisms of calcium waves. Cell Calcium 14, 736-745. https://doi.org/10.1016/0143-4160(93)90099-r (1993).

38. Decave, E., Garrivier, D., Brechet, Y., Fourcade, B. \& Bruckert, F. Shear flow-induced detachment kinetics of Dictyostelium discoideum cells from solid substrate. Biophys. J. 82, 2383-2395. https://doi.org/10.1016/S0006-3495(02)75583-5 (2002).

39. Yuan, F., Yang, C. \& Zhong, P. Cell membrane deformation and bioeffects produced by tandem bubble-induced jetting flow. Proc. Natl. Acad. Sci. USA 112, E7039-7047. https://doi.org/10.1073/pnas.1518679112 (2015).

40. Eastwood, A. L. et al. Tissue mechanics govern the rapidly adapting and symmetrical response to touch. Proc. Natl. Acad. Sci. USA 112, E6955-6963. https://doi.org/10.1073/pnas.1514138112 (2015).

41. Szabo, T. L. \& Wu, J. A model for longitudinal and shear wave propagation in viscoelastic media. J. Acoust. Soc. Am. 107, $2437-2446$. https://doi.org/10.1121/1.428630 (2000).

42. Miller, D. L. et al. Overview of therapeutic ultrasound applications and safety considerations. J. Ultrasound. Med. 31, 623-634. https://doi.org/10.7863/jum.2012.31.4.623 (2012).

43. O’Brien, W. D. Jr. Ultrasound-biophysics mechanisms. Prog. Biophys. Mol. Biol. 93, 212-255. https://doi.org/10.1016/j.pbiomolbio 2006.07.010 (2007)

44. Fletcher, D. A. \& Mullins, R. D. Cell mechanics and the cytoskeleton. Nature 463, 485-492. https://doi.org/10.1038/nature08908 (2010).

45. Harland, C. W., Bradley, M. J. \& Parthasarathy, R. Phospholipid bilayers are viscoelastic. Proc. Natl. Acad. Sci. USA 107, 1914619150. https://doi.org/10.1073/pnas.1010700107 (2010).

46. Groves, J. T. \& Kuriyan, J. Molecular mechanisms in signal transduction at the membrane. Nat. Struct. Mol. Biol. 17, 659-665. https://doi.org/10.1038/nsmb.1844 (2010).

47. Cox, C. D., Bavi, N. \& Martinac, B. Origin of the force: the force-from-lipids principle applied to Piezo channels. Curr. Top. Membr. 79, 59-96. https://doi.org/10.1016/bs.ctm.2016.09.001 (2017).

48. Dubin, A. E. et al. Endogenous Piezol can confound mechanically activated channel identification and characterization. Neuron 94, 266-270. https://doi.org/10.1016/j.neuron.2017.03.039 (2017).

49. Grynkiewicz, G., Poenie, M. \& Tsien, R. Y. A new generation of Ca2+ indicators with greatly improved fluorescence properties. J. Biol. Chem. 260, 3440-3450 (1985).

\section{Acknowledgements}

This work was supported in part by National Institutes of Health through Grant 5R37-DK052985-24. MingYen Hsiao was supported by the National Taiwan University Hospital for one year of postdoctoral fellowship at Duke University. We would like to express our gratitude to Dr. Jorg Grandl of Duke Neurobiology for providing the P1KO cell line and Piezol plasmid used in this study. We also want to thank Eric Stach for designing the VD-SAW holder.

\section{Author contributions}

D.L. and P.Z. originally conceived the study concept. D.L. designed and fabricated the VD-SAW transducer. D.L. and M.H. cultured HEK293T cells and performed experiments. D.L., M.H., and G.X. performed image analysis. G.X. and D.L. performed the numerical simulation. D.L. and P.Z. analyzed the resultant data and wrote the paper.

\section{Competing interests}

The authors declare no competing interests.

\section{Additional information}

Supplementary Information The online version contains supplementary material available at https://doi. org/10.1038/s41598-020-78553-2.

Correspondence and requests for materials should be addressed to P.Z.

Reprints and permissions information is available at www.nature.com/reprints.

Publisher's note Springer Nature remains neutral with regard to jurisdictional claims in published maps and institutional affiliations. 
(c) (i) Open Access This article is licensed under a Creative Commons Attribution 4.0 International cc) License, which permits use, sharing, adaptation, distribution and reproduction in any medium or format, as long as you give appropriate credit to the original author(s) and the source, provide a link to the Creative Commons licence, and indicate if changes were made. The images or other third party material in this article are included in the article's Creative Commons licence, unless indicated otherwise in a credit line to the material. If material is not included in the article's Creative Commons licence and your intended use is not permitted by statutory regulation or exceeds the permitted use, you will need to obtain permission directly from the copyright holder. To view a copy of this licence, visit http://creativecommons.org/licenses/by/4.0/.

(C) The Author(s) 2021 